\title{
Optics Requirements for X-ray Astronomy \& Developments at the Marshall Space Flight Center
}

\section{Birth of X-Ray Astronomy}

- In 1962, Riccardo Giacconi and colleagues at AS\&E flew sounding rocket to look at $x$-ray fluorescence from the moon

- Lunar signal was overshadowed by very strong emission from the Scorpious region

- Discovered the first extra-solar $x$-ray source, Sco $X-1$, and pervasive $x$-ray background

- This was the effective birth of $x$-ray astronomy
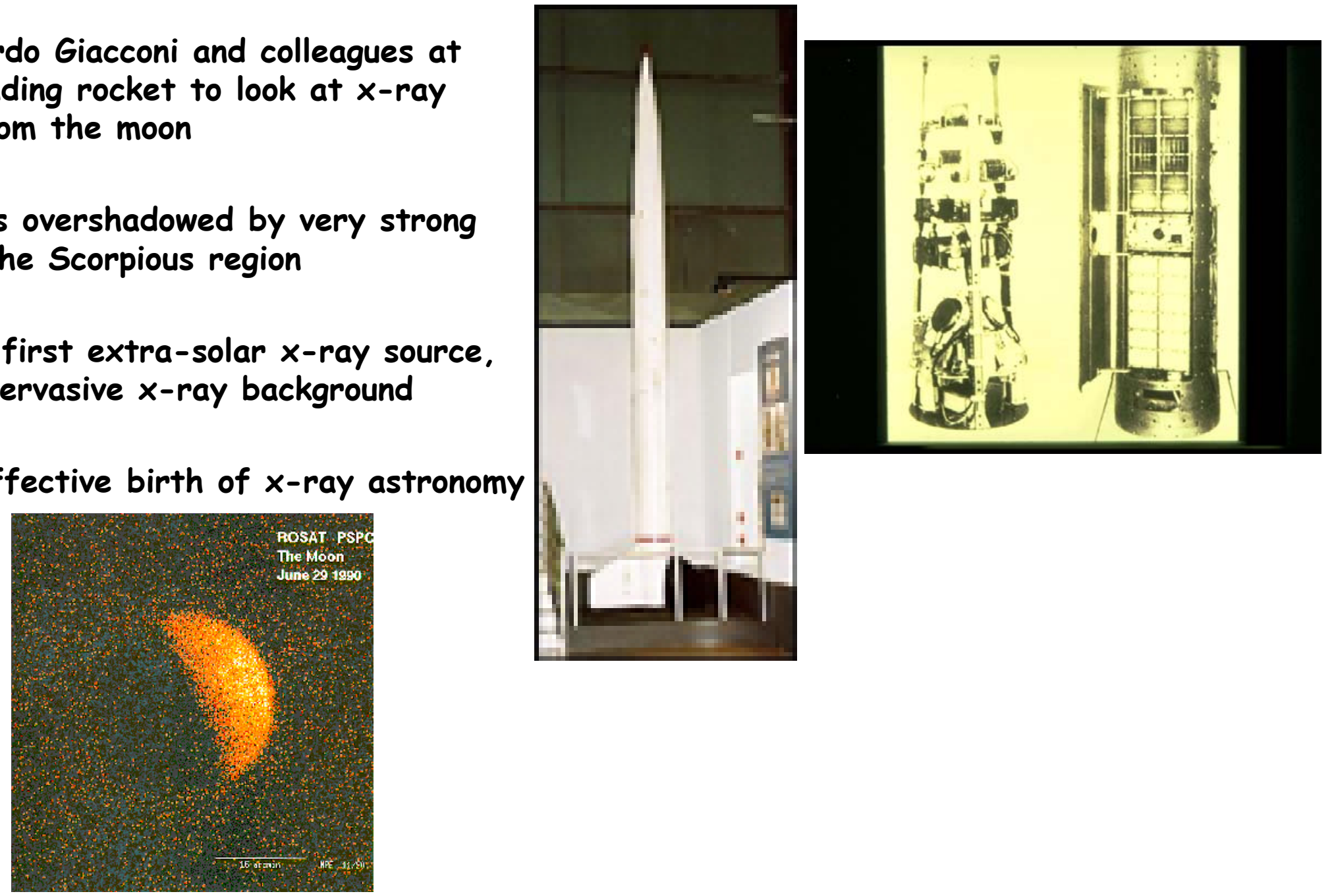
The Atmosphere Protects Us

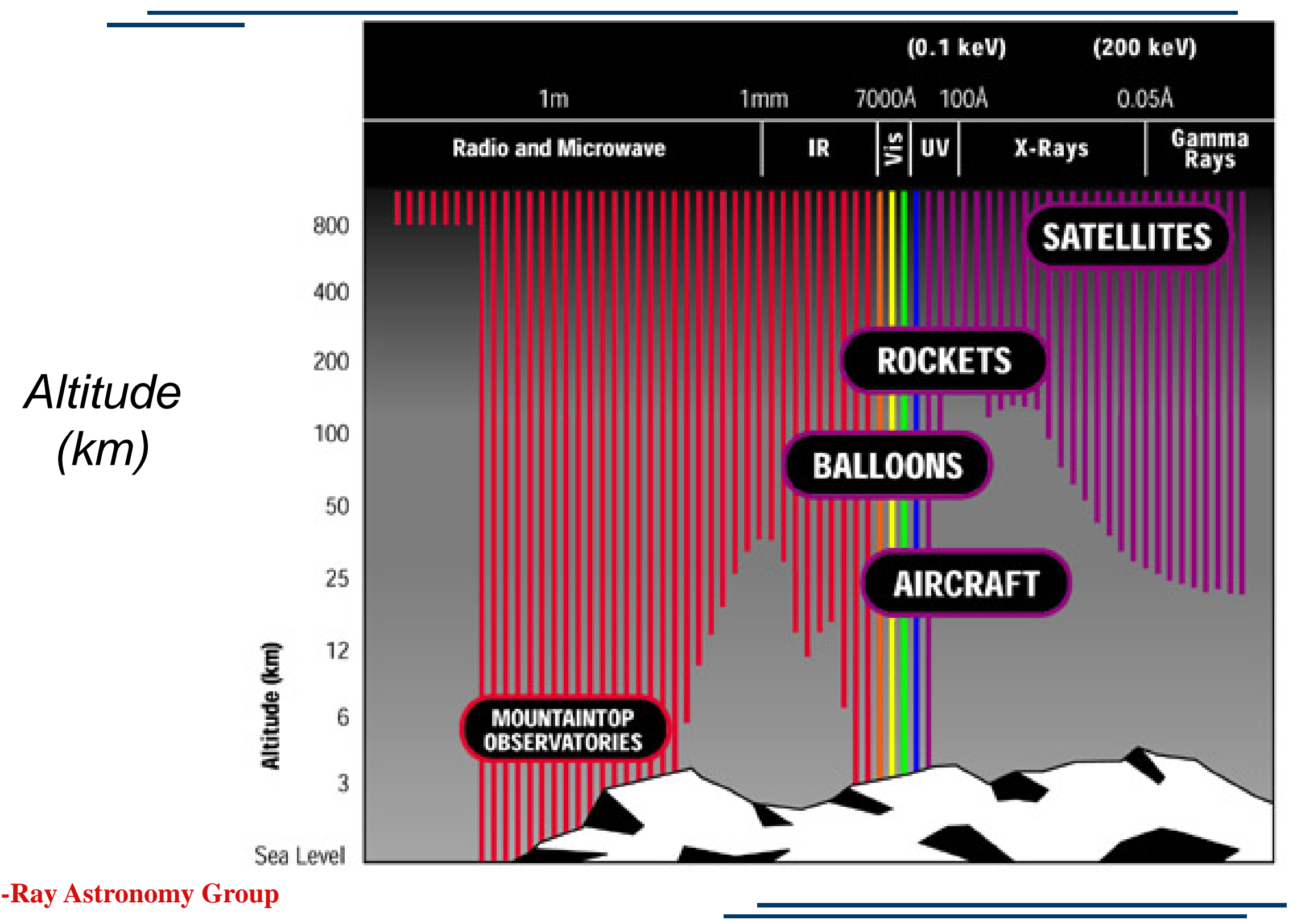




\section{X-Ray Astronomy}

First X-Ray Satellite

The UHURU spacecraft was launched in 1970

It weighed just 140 pounds, not much more than the rocket experiment

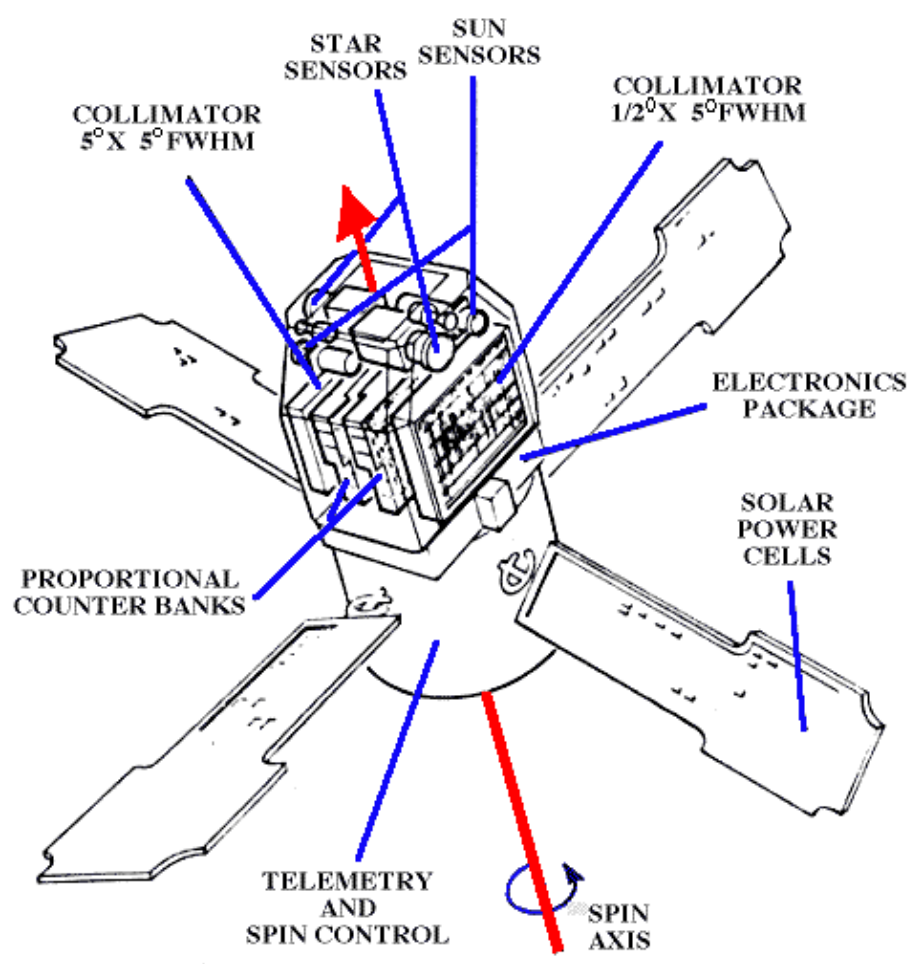

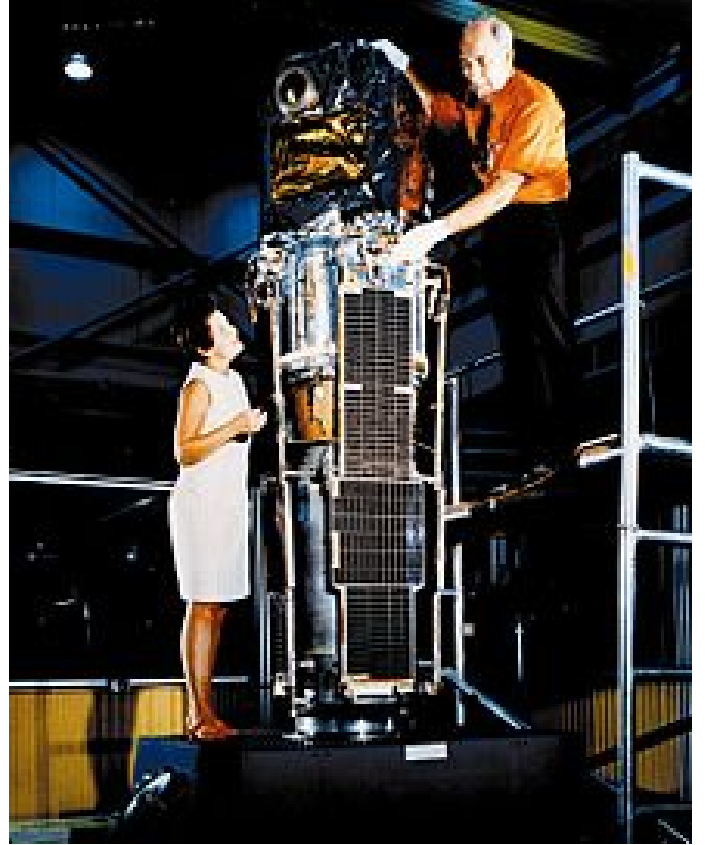

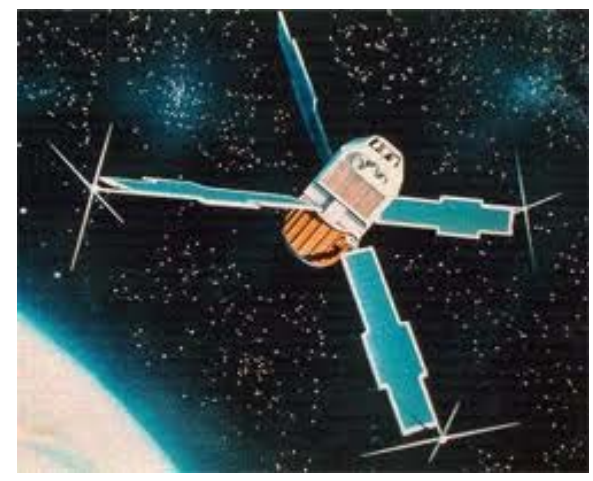




\section{X-Ray Astronomy}

\section{UHURU}

Used a simple collimator system, to locate $x$-ray sources in sky

It operated for 3 years and discovered 339 sources in the whole sky
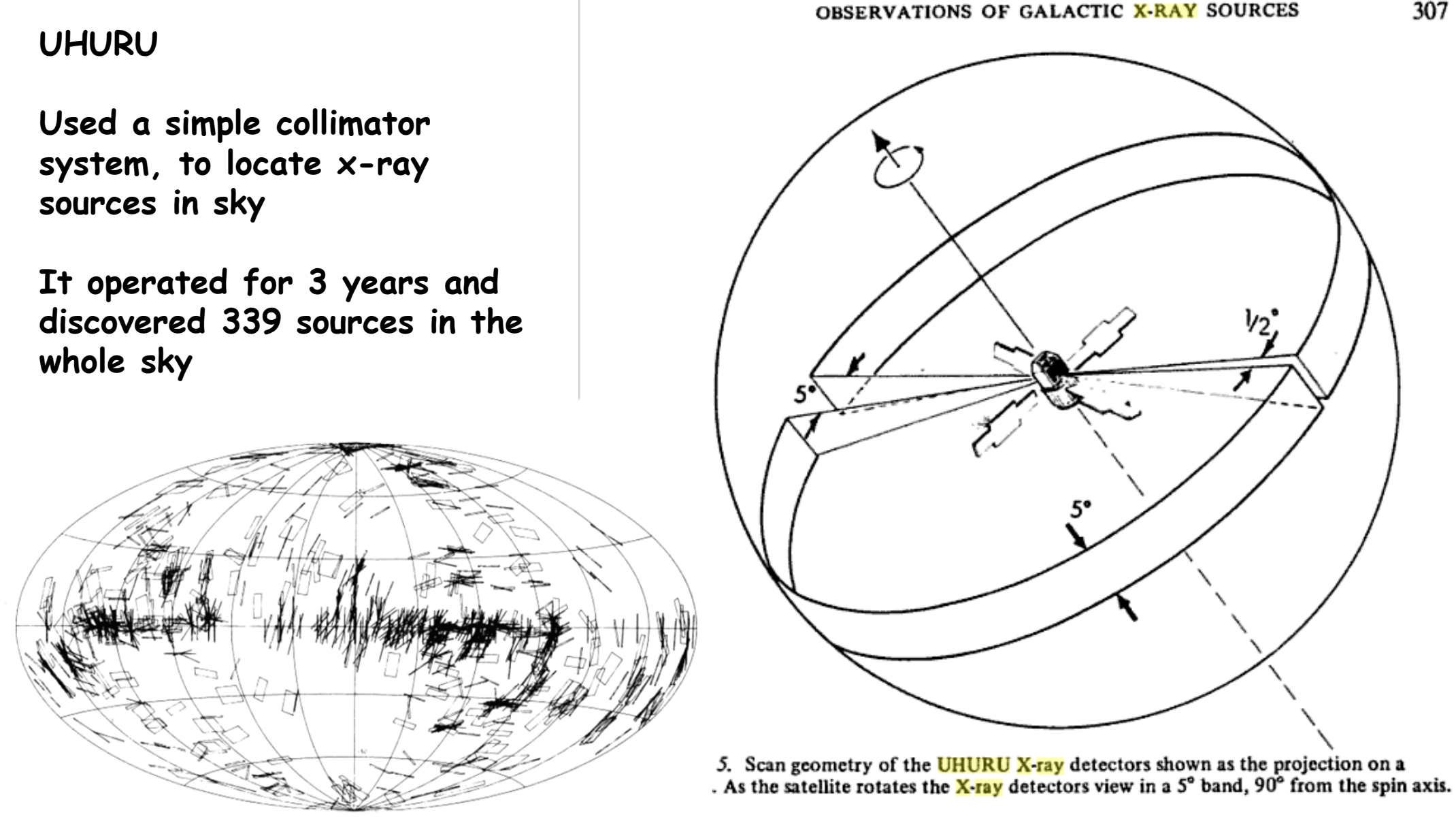

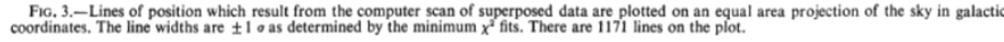

As the satellite rotates the $\mathrm{X}-\mathrm{ray}$ detectors view in a $5^{\circ}$ band, $90^{\circ}$ from the spin axis.

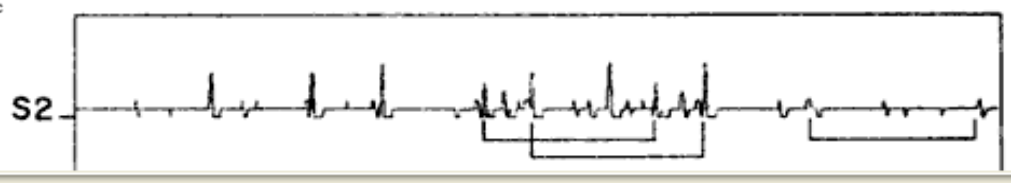

X-Ray Astronomy Group 


\section{X-Ray Astronomy}

\section{Early observations}

From these early observations a picture emerged of a typical $x$-ray source:

A compact object (neutron star, black hole, white dwarf) orbiting around a normal star

Matter streams down on to the compact object forming an accretion disk

As the matter spirals down and is compressed it gets very hot and emits $x$ rays

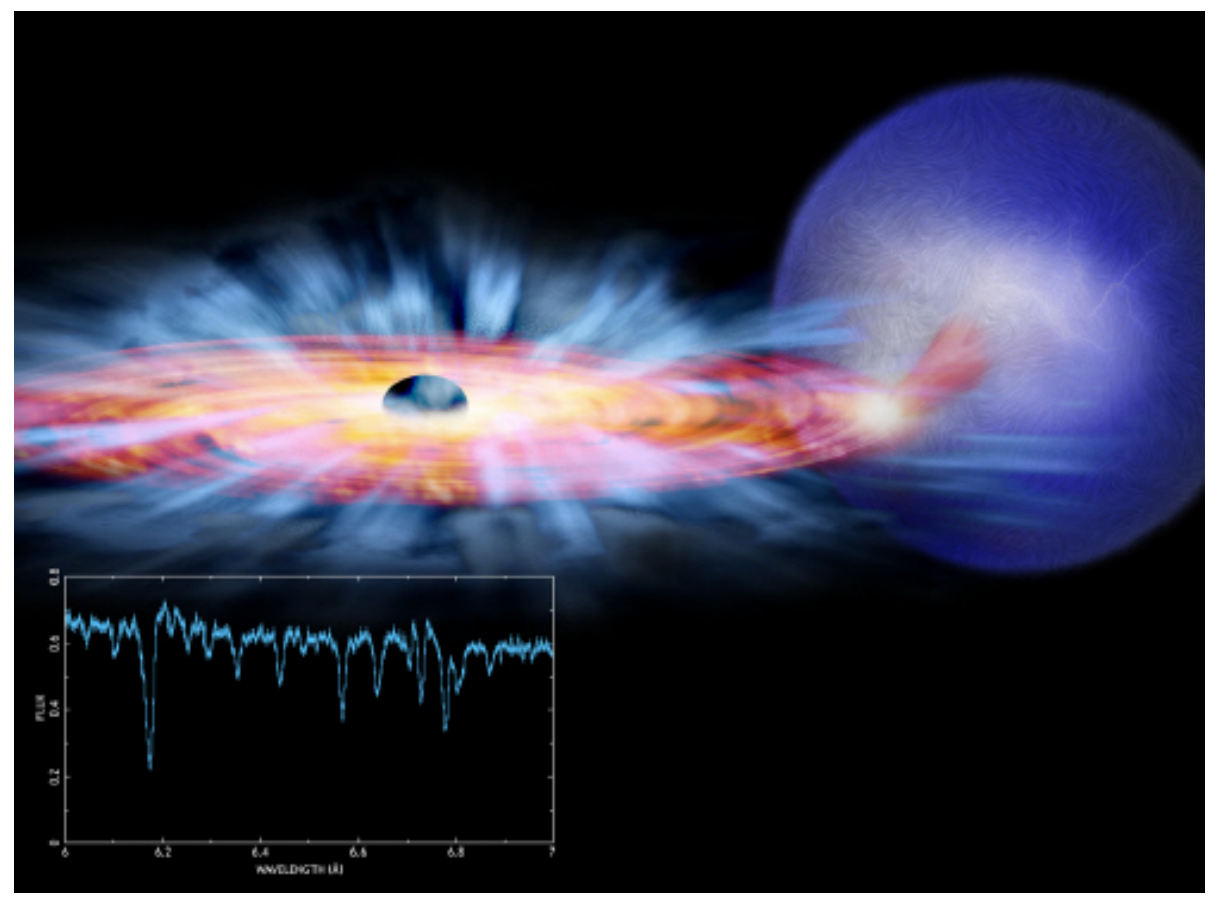




\section{Today.. The Chandra Observatory}

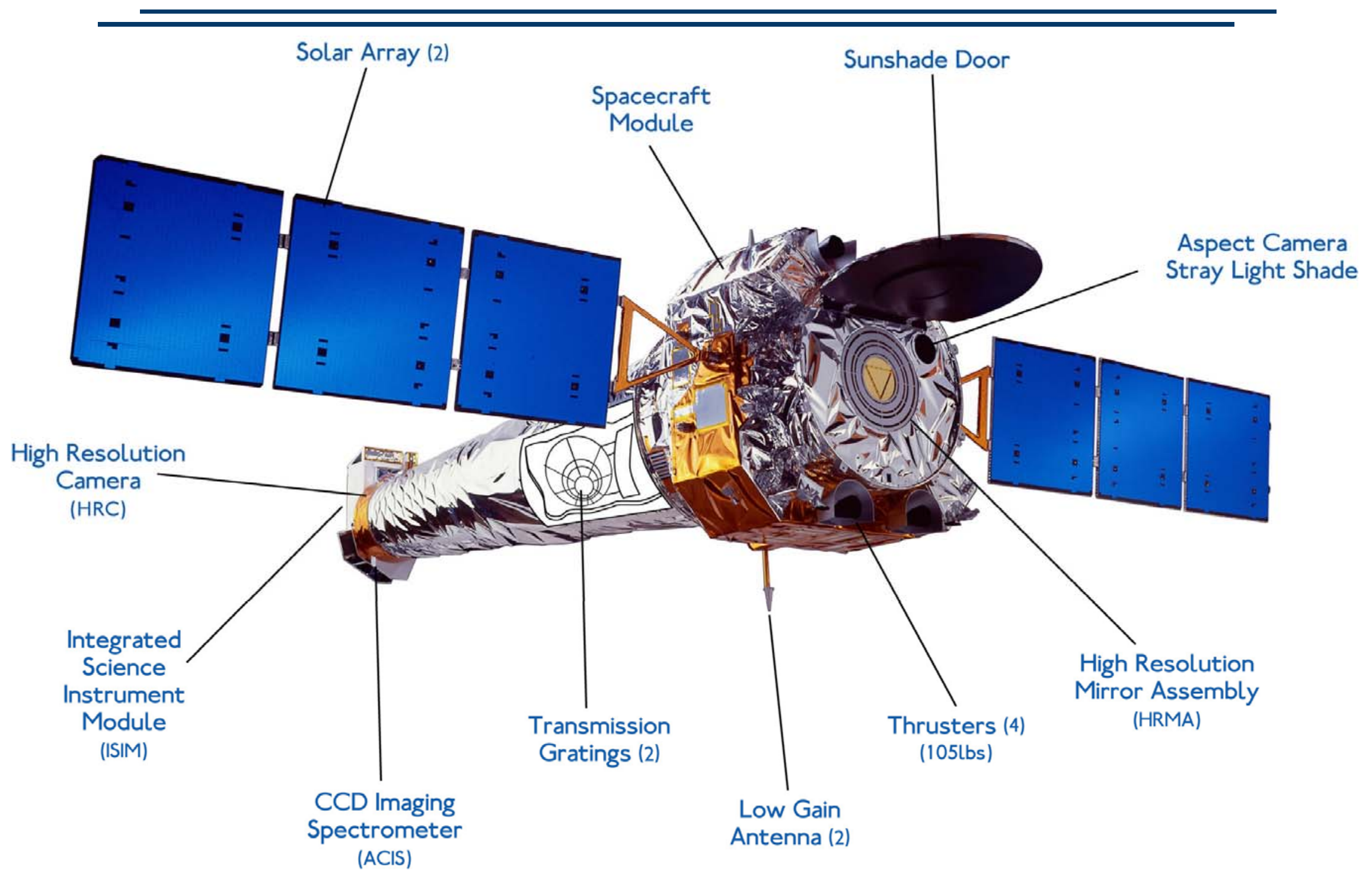

X-Ray Astronomy Group 


\section{Today.. The Chandra Observatory}

- School-bus-size x-ray observatory

- 100,000 times more powerful than UHURU

- Uses special mirrors to form highly detailed images

- In deep fields, more than 1000 new sources per square degree

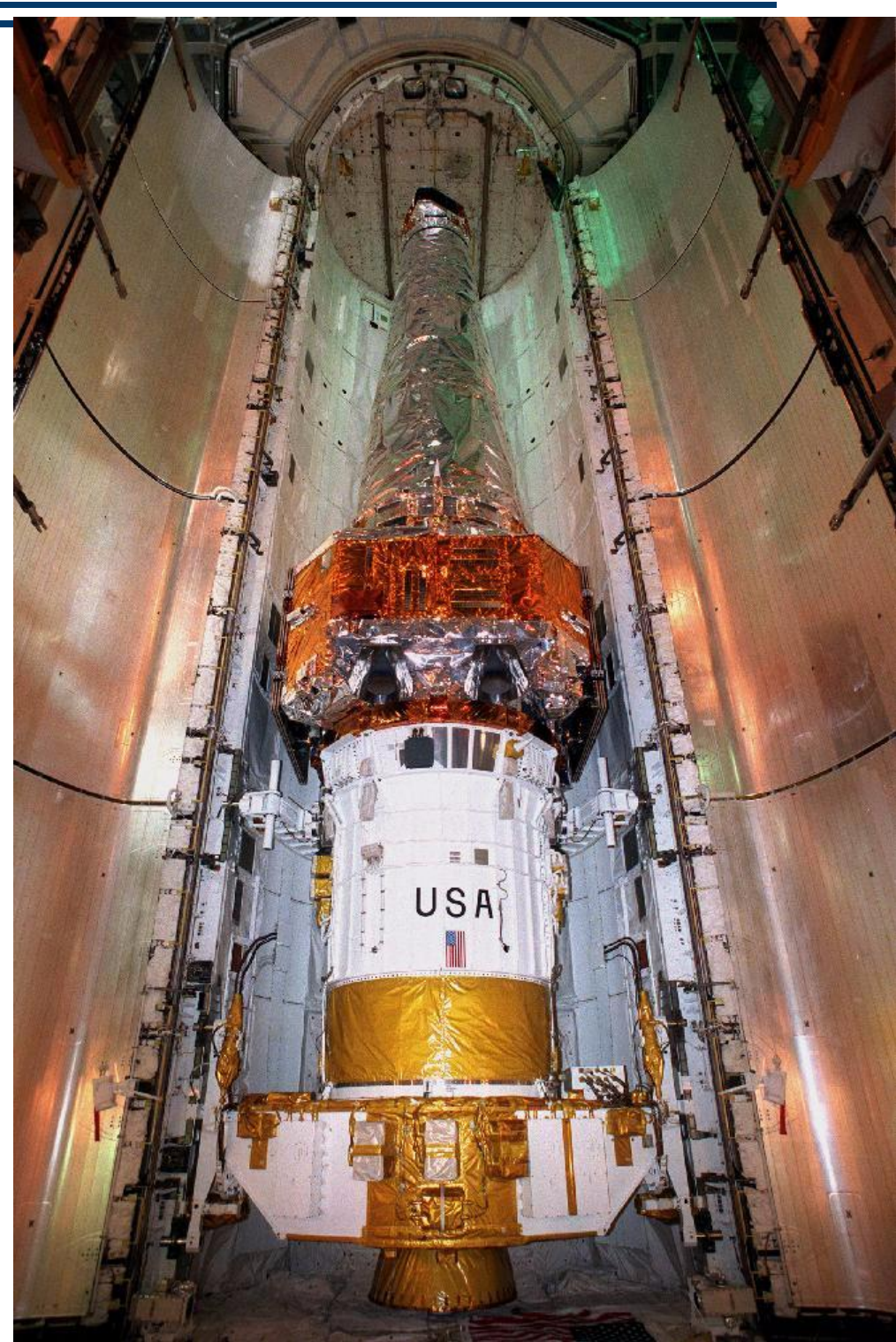




\section{Chandra Images : Cas-A Supernova Remnant}

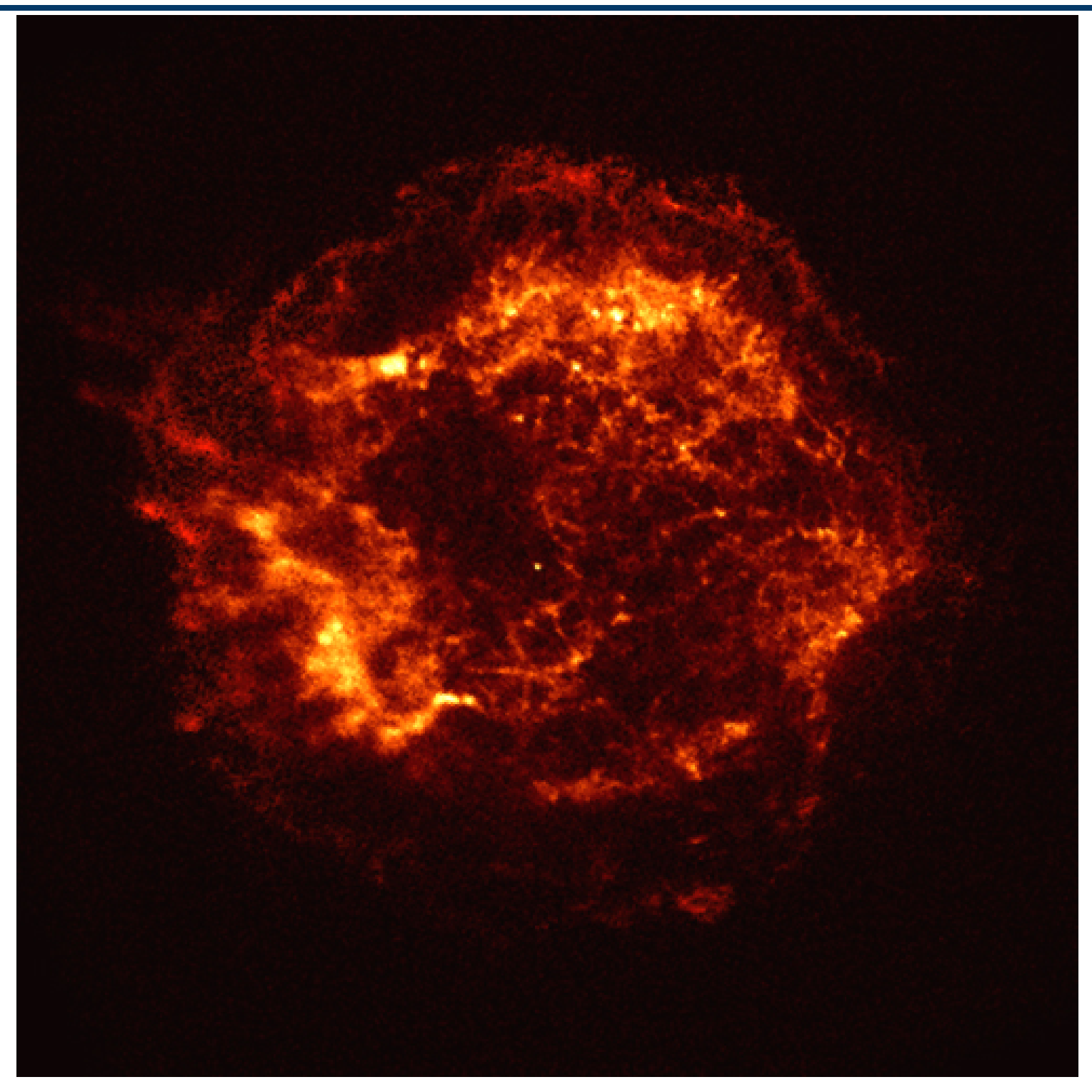




\section{Chandra Images : Center of our Galaxy}

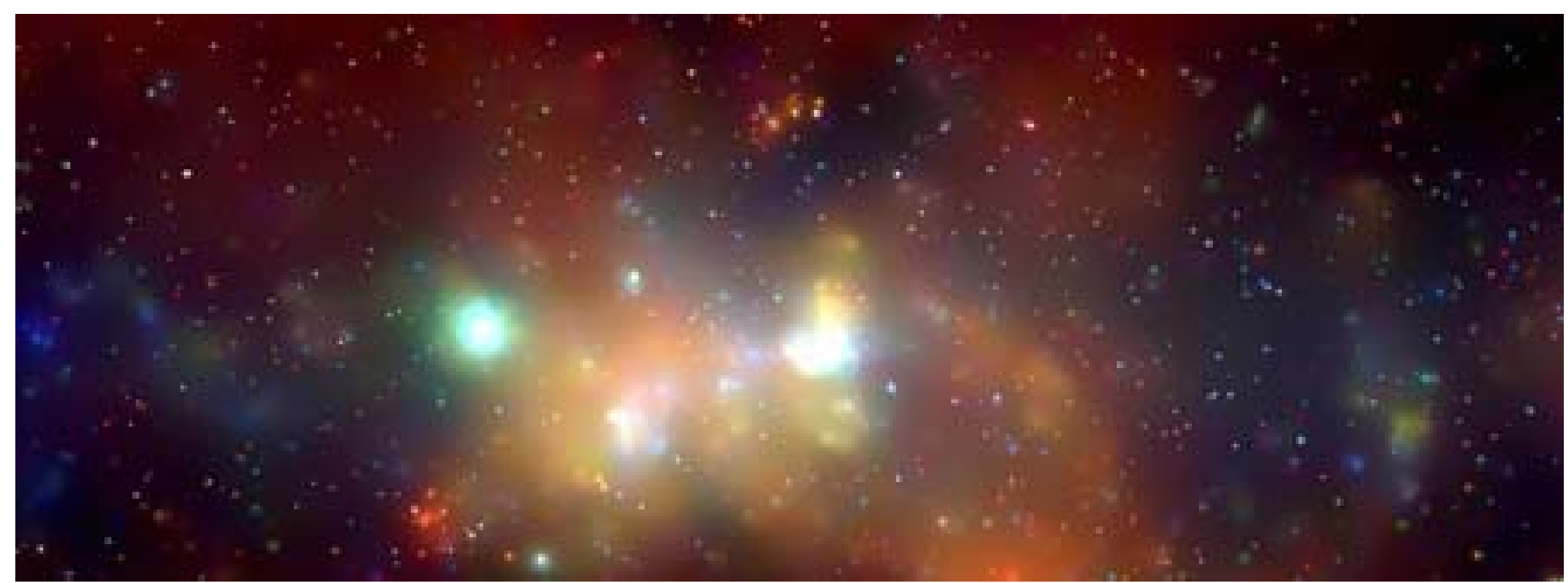


The Crab Nebula and its Pulsar 


\section{X-Ray Optics}

\section{Why focus $x$ rays ?}

1) Imaging - obvious

2) Background reduction

- Signal from cosmic sources very faint, observed against a large background

- Background depends on size of detector and amount of sky viewed

> Concentrate flux from small area of sky on to small detector

$\Rightarrow$ enormous increase in sensitivity

First dedicated $x$-ray astronomy satellite - UHURU mapped 340 sources with large area detector (no optics)

Chandra observatory - same collecting area as UHURU

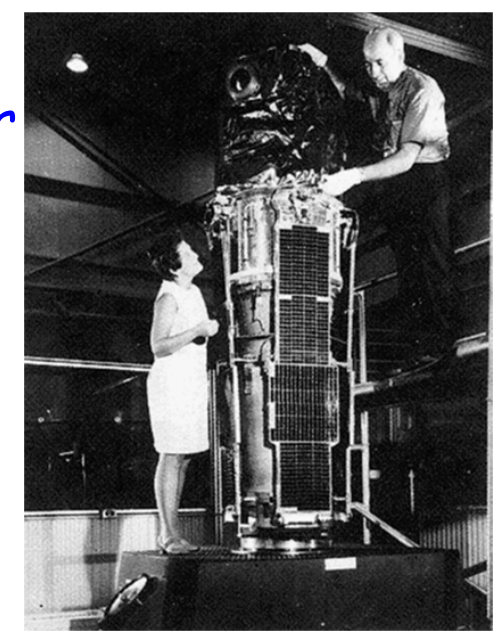

$>5$ orders of mag more sensitivity -- 1,000 sources / sq degree in deep fields

> 1 background count / keV year!

\section{$\underline{X \text {-Ray Optics has revolutionized } x \text {-ray astronomy }}$}




\section{X-Ray Optics}

- X Rays undergo total external reflection at shallow graze angles

- Critical angle (away from absorption edges)

$$
>\sim \theta_{c}(d e g)=0.93 \lambda(\mathrm{nm}) \sqrt{ }\left(\rho\left(\mathrm{g} / \mathrm{cm}^{3}\right)\right.
$$

- Can use this phenomenon in focusing x-ray telescopes

Reflect $x$ rays to a common focus

Single parabola gives severe off-axis distortions, ... Wolter-1 geometry adopted
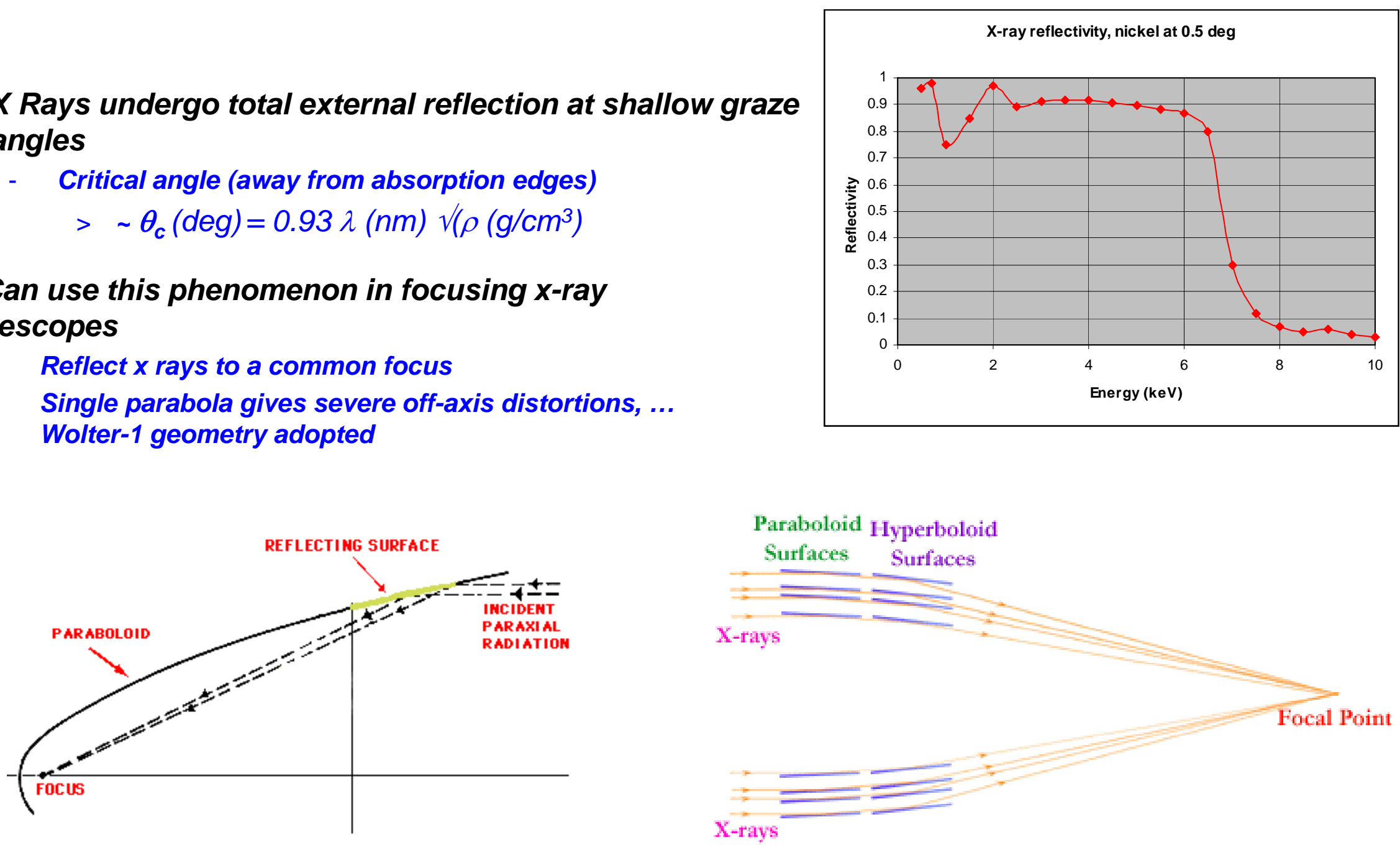

X-Ray Astronomy Group 


\section{Approaches to Fabrication}

- $X$-ray optics are very challenging to fabricate. Because of very short wavelength of $x$-rays the mirror surface must be smooth to $\sim 0.5 \mathrm{~nm} \mathrm{rms}$.

- Also, for good angular resolution, the figure must be accurate to < 1 micron.

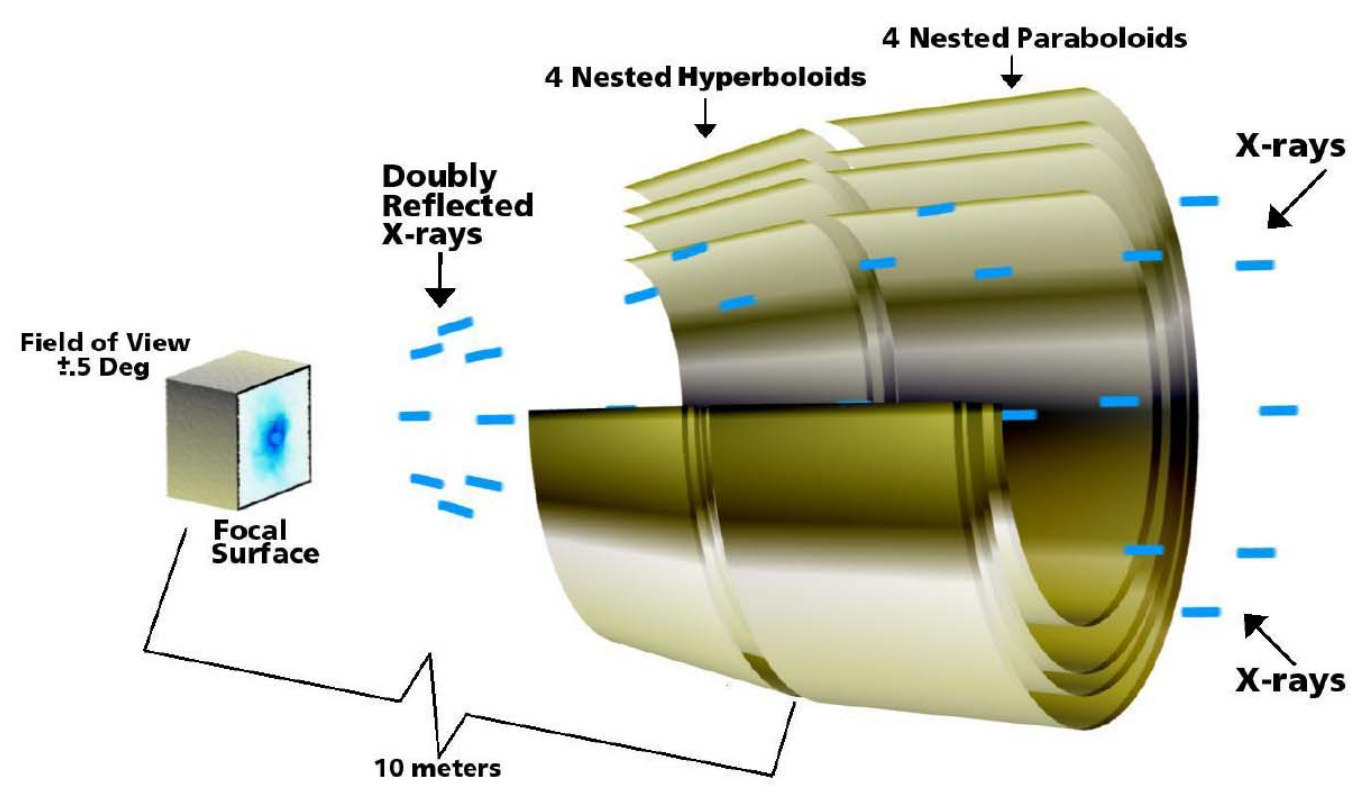




\section{Approaches to Fabrication}
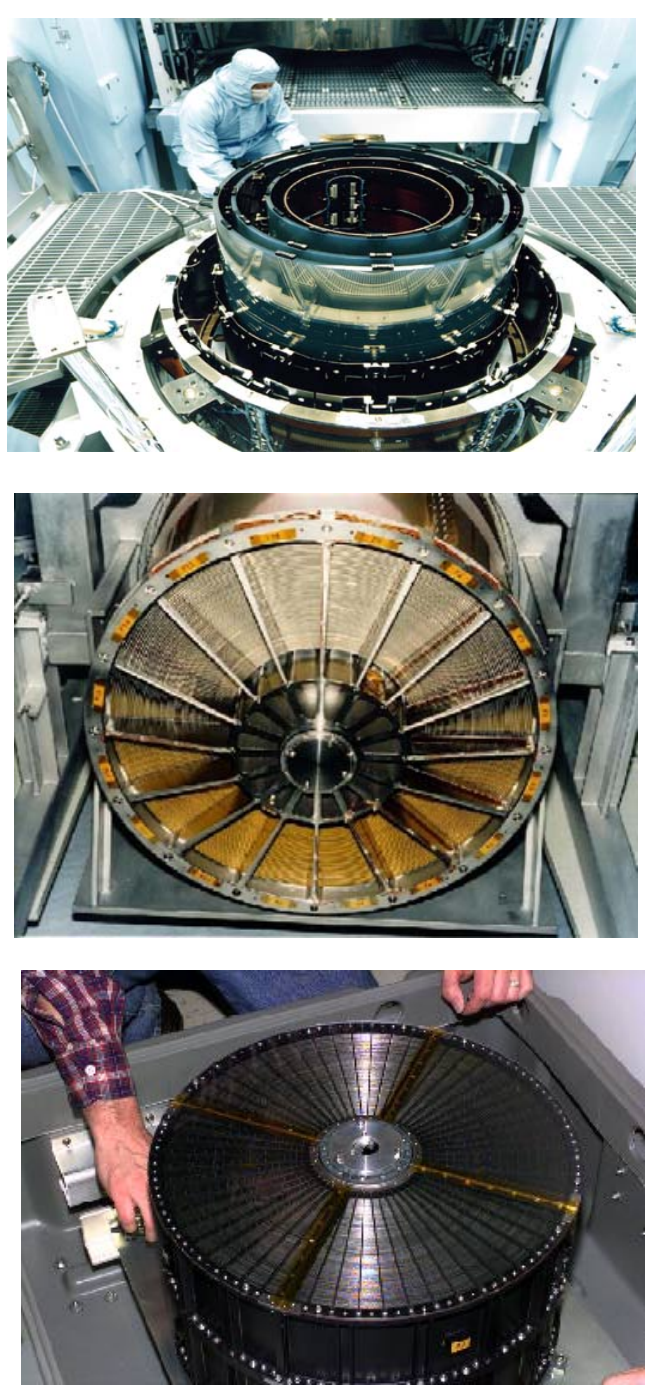

\section{Segmented foil}

$$
\text { ASTRO-E, ASTRO-F, ASCA, BBXRT }
$$

Advantage: Light weight, low cost

Disadvantage: Relatively poor angular resolution (arc-minute-level)
Classical Optical grinding and polishing

Chandra, Rosat, Einstein

Advantage: Superb angular resolution

Disadvantage: High cost, large mass, difficult to nest

\section{Electroformed Nickel Replication}

\section{XMM, JETX/Swift, SAX}

Advantage: High nesting factor, good resolution

Disadvantage: Medium cost, mass (high density of nickel) 


\section{Approaches: Chandra}

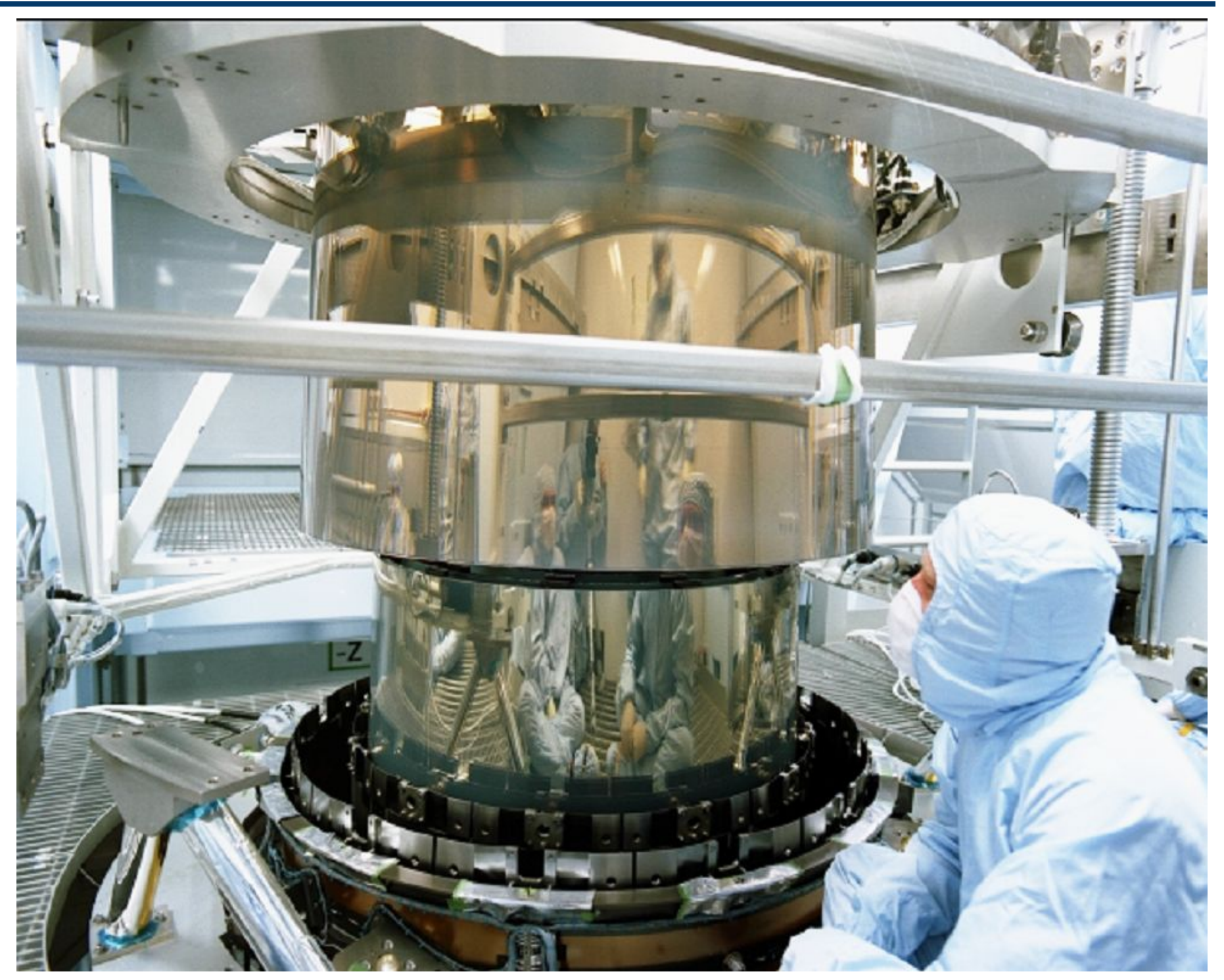




\section{Approaches: Chandra}

- Fabricated using thick ceramic, which is meticulously polished and figured, one shell at a time.

- Obtain superb angular resolution -.--- 0.5 arcsec HPD

- But very costly to fabricate $(\$ 500 \mathrm{M})$ and very heavy $(1000 \mathrm{~kg})$

- So, other approaches to $x$-ray optics have been used that trade the superb angular resolution for ease of fabrication and lighter weight (and cost) 


\section{Approaches: Foil Optics}

- Fabricated using very thin aluminum foils as reflectors. Foils held in slots in housing.

- Obtain poor angular resolution - 1-2 arcminute HPD

- But extremely light weight allowing for many individual reflectors, and thus large collecting area
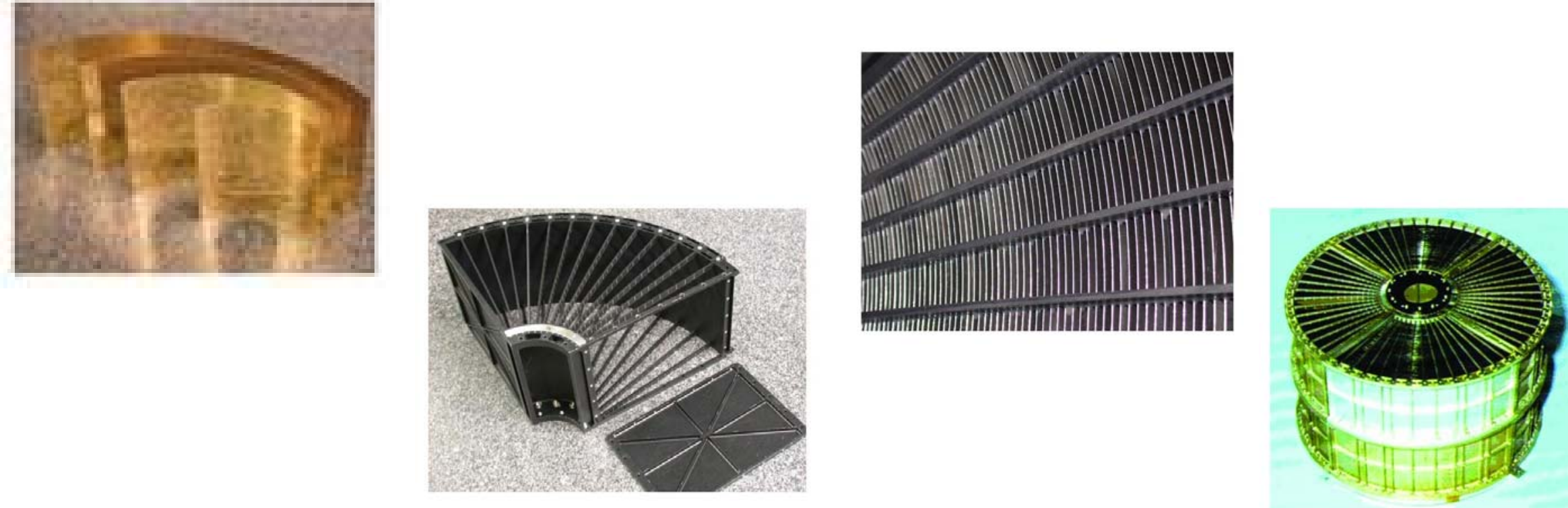


\section{Approaches: Electroformed Nickel Replication (ENR)}

- Electroform thin nickel shells from superpolished and figured masters (mandrels)

- Obtain intermediate level angular resolution ( 15 arcsec HPD)

- But considerably less expensive to fabricate and considerably lighter

- Electroformed nickel optics are being fabricated at MSFC for various programs. 


\section{Challenges for Future Missions}

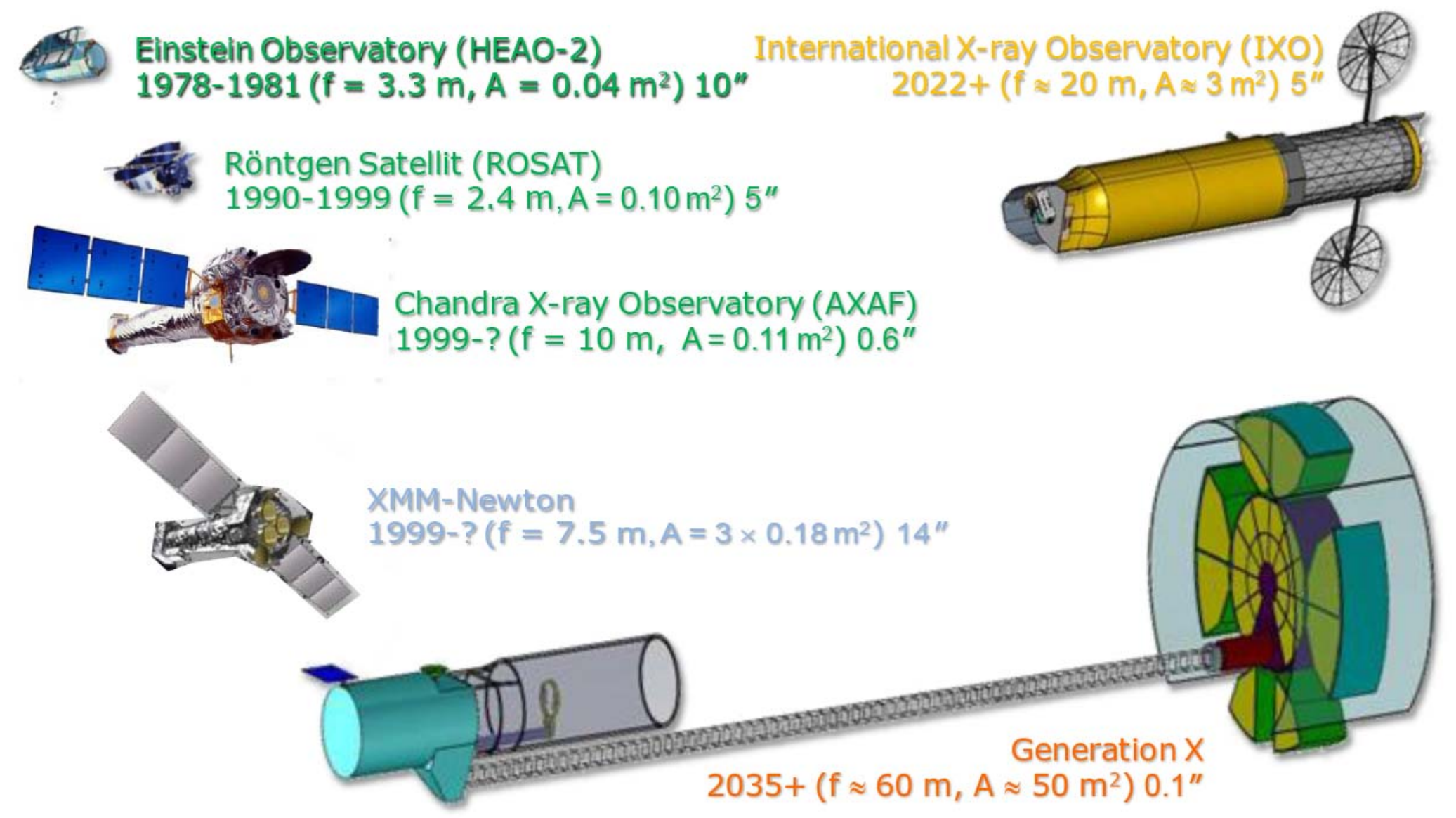




\section{Mirror Fabrication for (near) Future Missions}

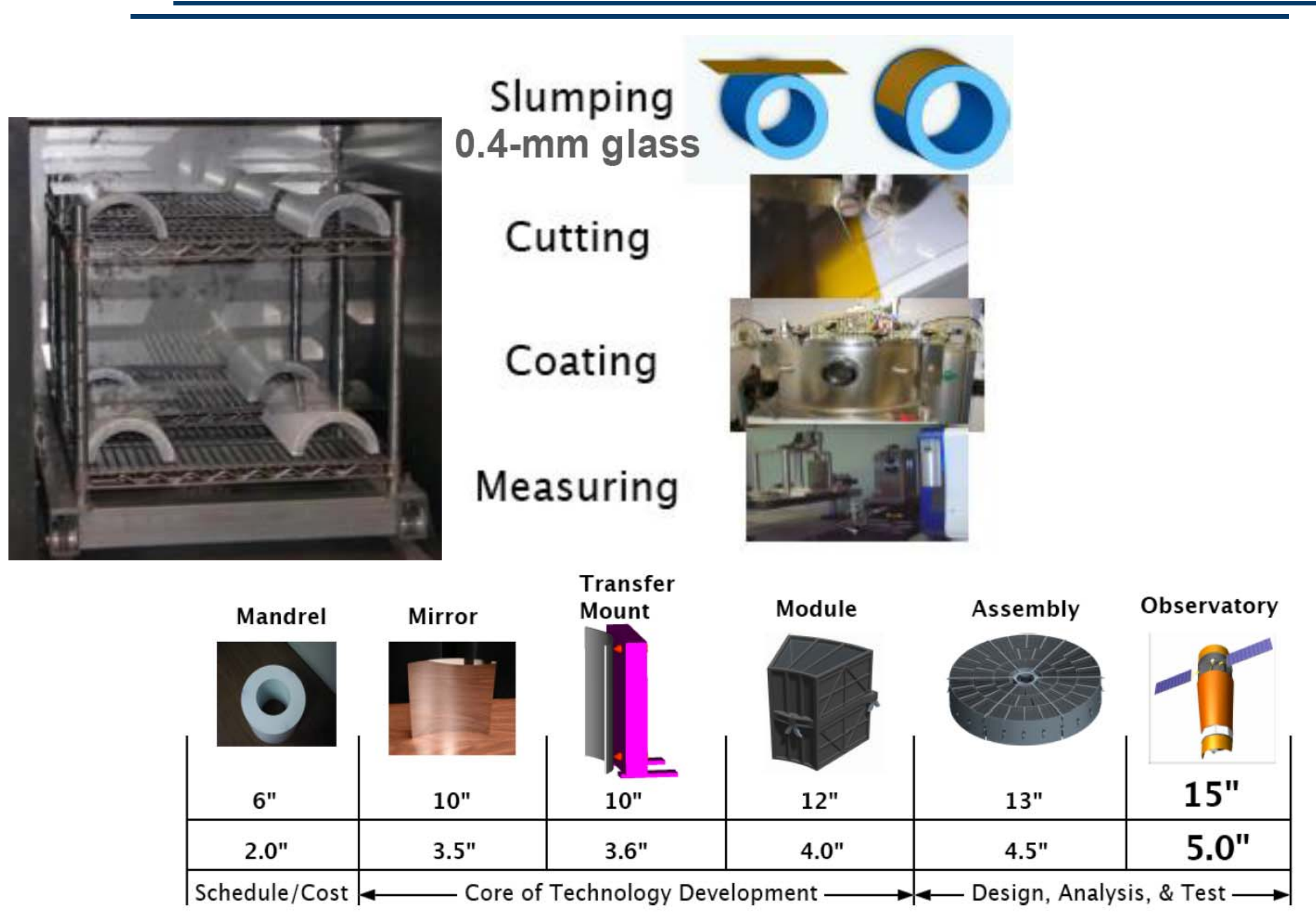

X-Ray Astronomy Group 


\section{Mirrors for (far) Future Missions - Active Optics}

How can we achieve sub-arcsec resolution with thin optics?

One option is to utilize active control of mirror figure, as is done in optical astronomy
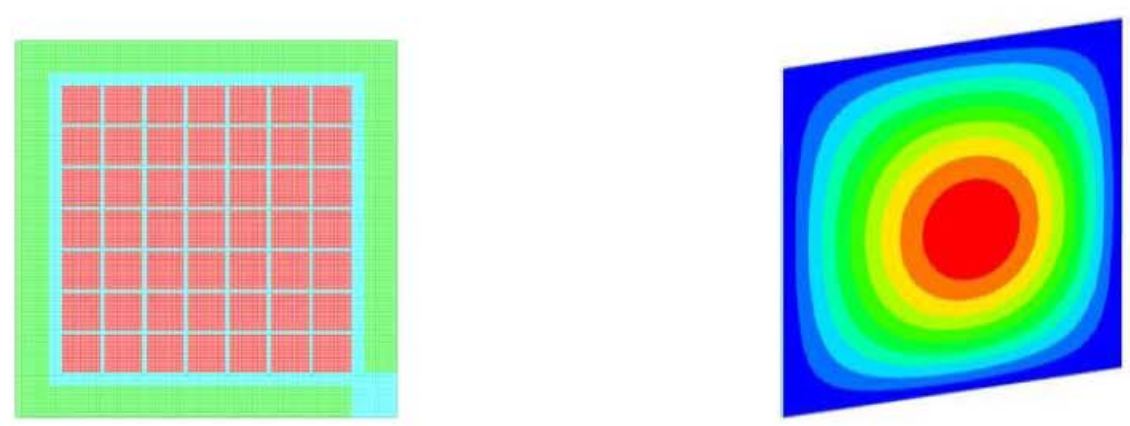

$\otimes$
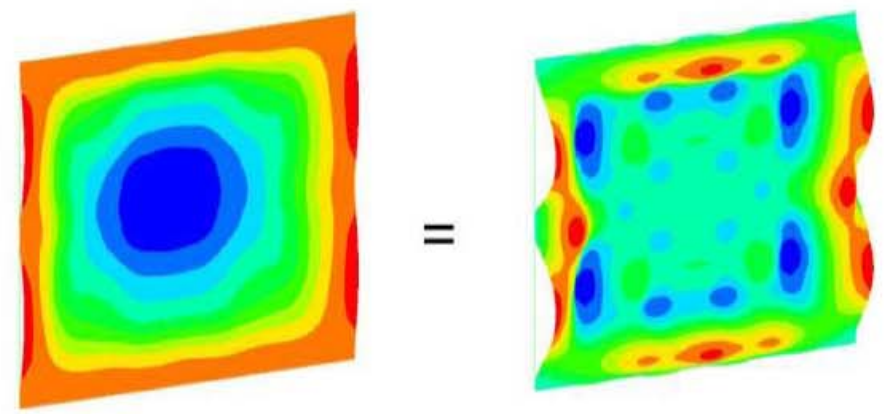

Figure 3: By appropriate adjustment of an array of surface-tangential actuators, a controlled deformation corrects the figure of a distorted mirror at the longer spatial wavelengths. The left panel schematically represents such an array on the back of a thin mirror segment. The right panel illustrates the application of a correction map to an error map, resulting in a mirror with low-spatial-frequency distortions removed. 


\section{Mirrors for (far) Future Missions - Active Optics}

Technique has been used for synchrotron $x$-ray optics, but in its infancy in $x$-ray astronomy.

- Difficulty is the football-field-size areas that must be controlled.

- Algorithms needed that converge

- Power requirements and stability. etc
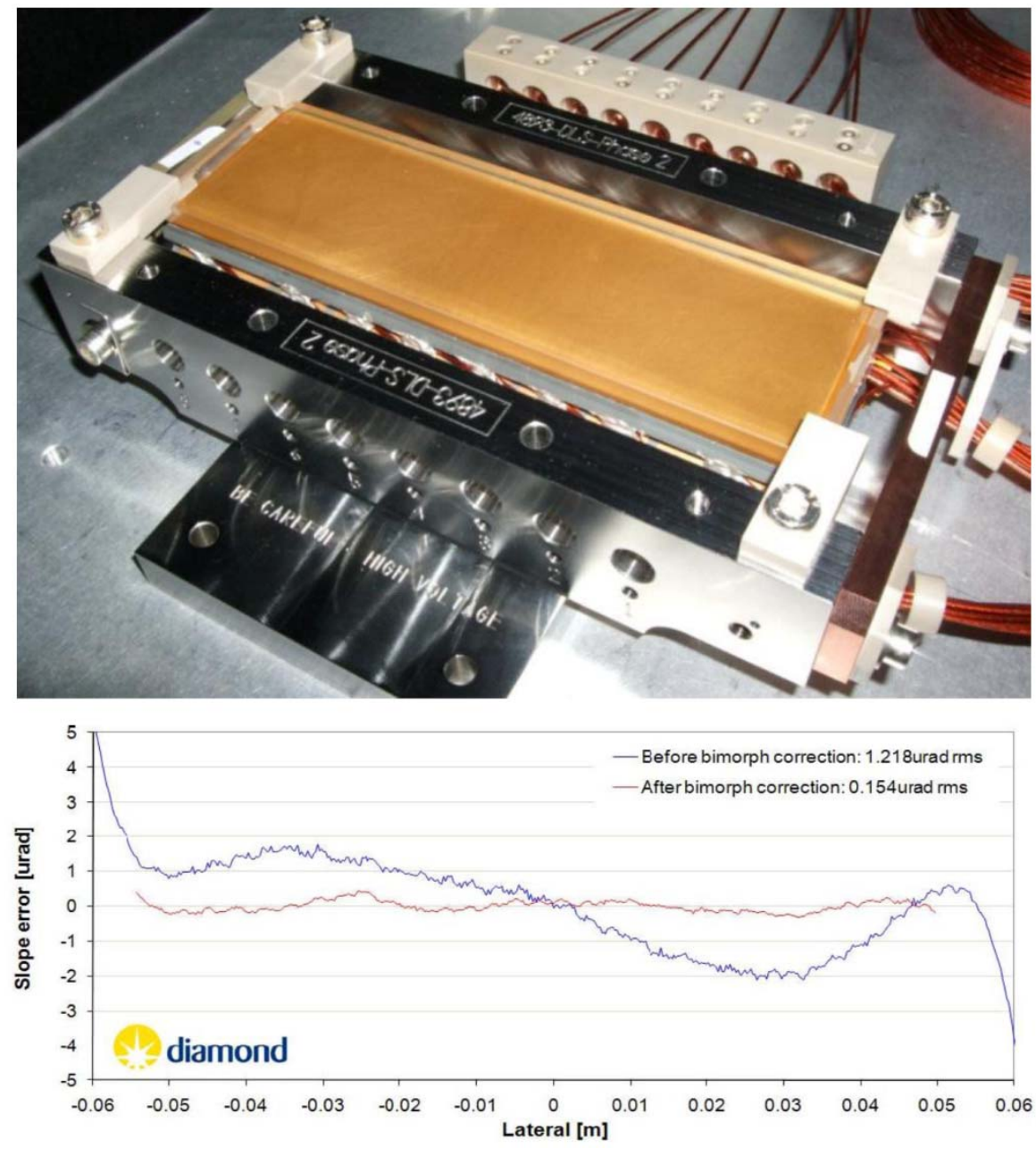


\section{Mirrors for Future Missions - Differential Deposition}

Vacuum deposit a filler material to compensate for figure imperfections Proof of concept work underway at MSFC

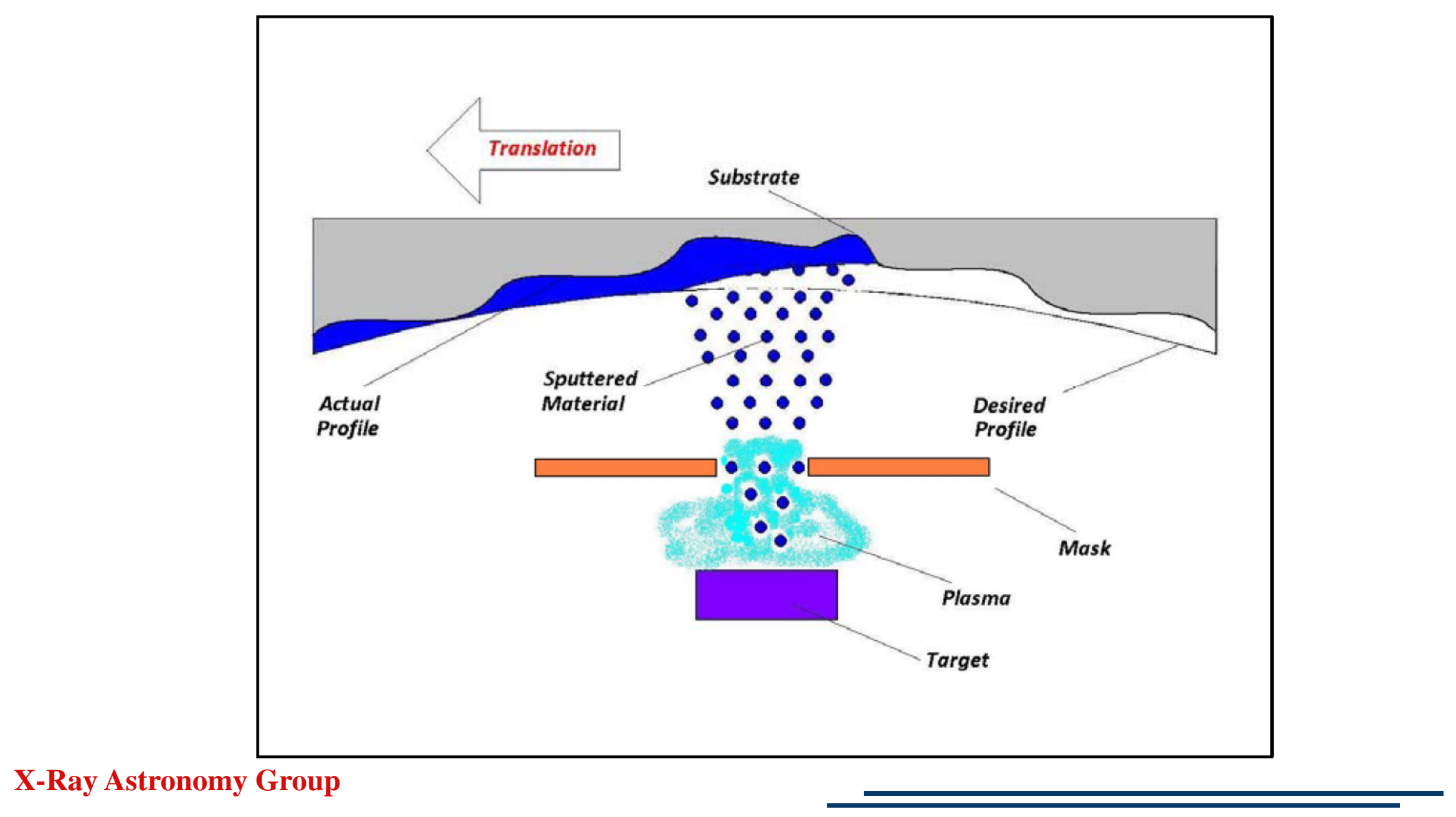




\section{Process sequence - differential deposition}

X-ray testing

Surface profile metrology

Develop correction profile "Hitmap"

Simulations - translation velocity of shell

Differential deposition

Surface profile metrology

X-ray testing 


\section{Theoretical performance improvement}

Simulations performed on $X$-ray shell profile of 8 arc sec simulated HPD

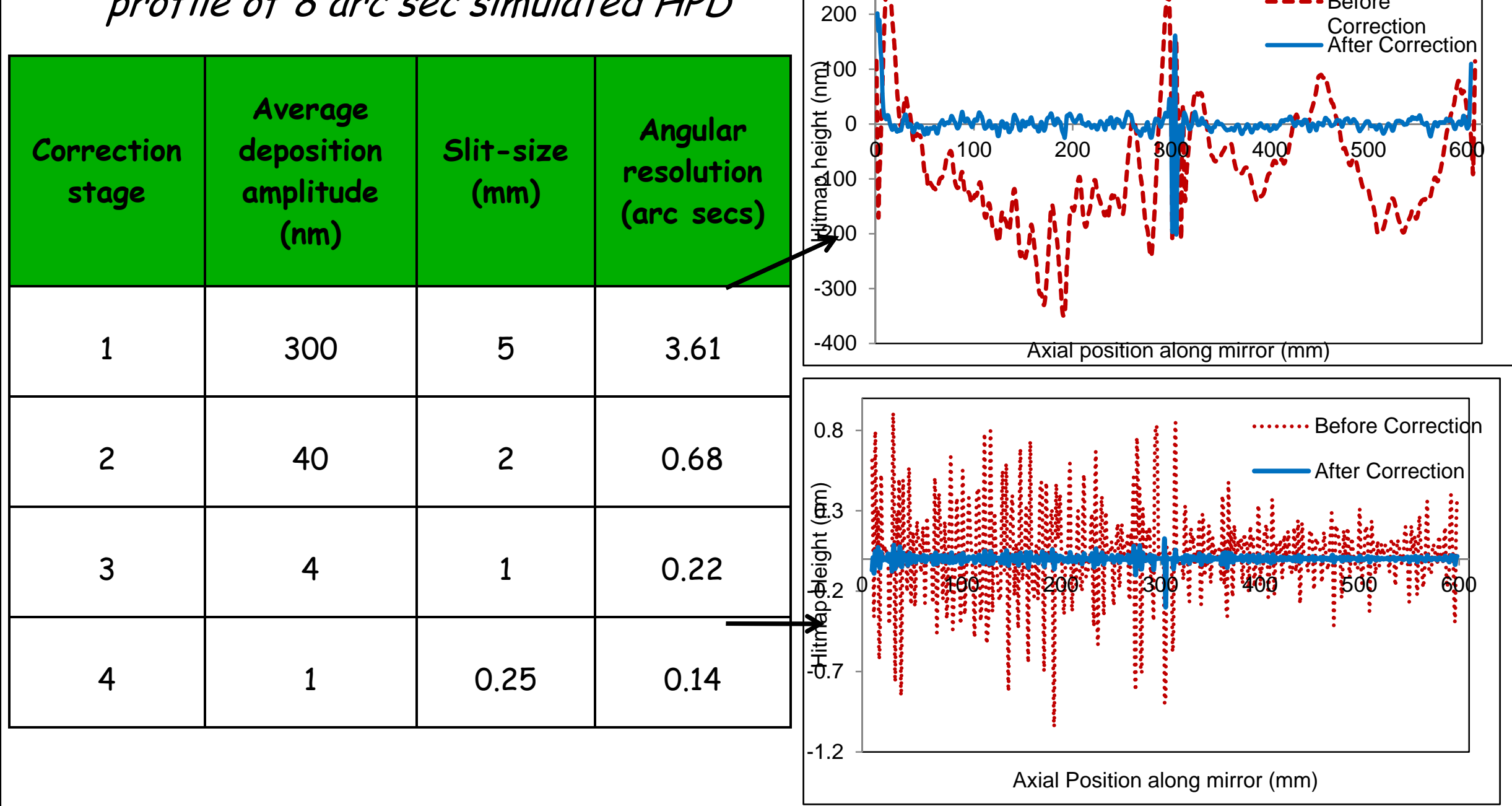
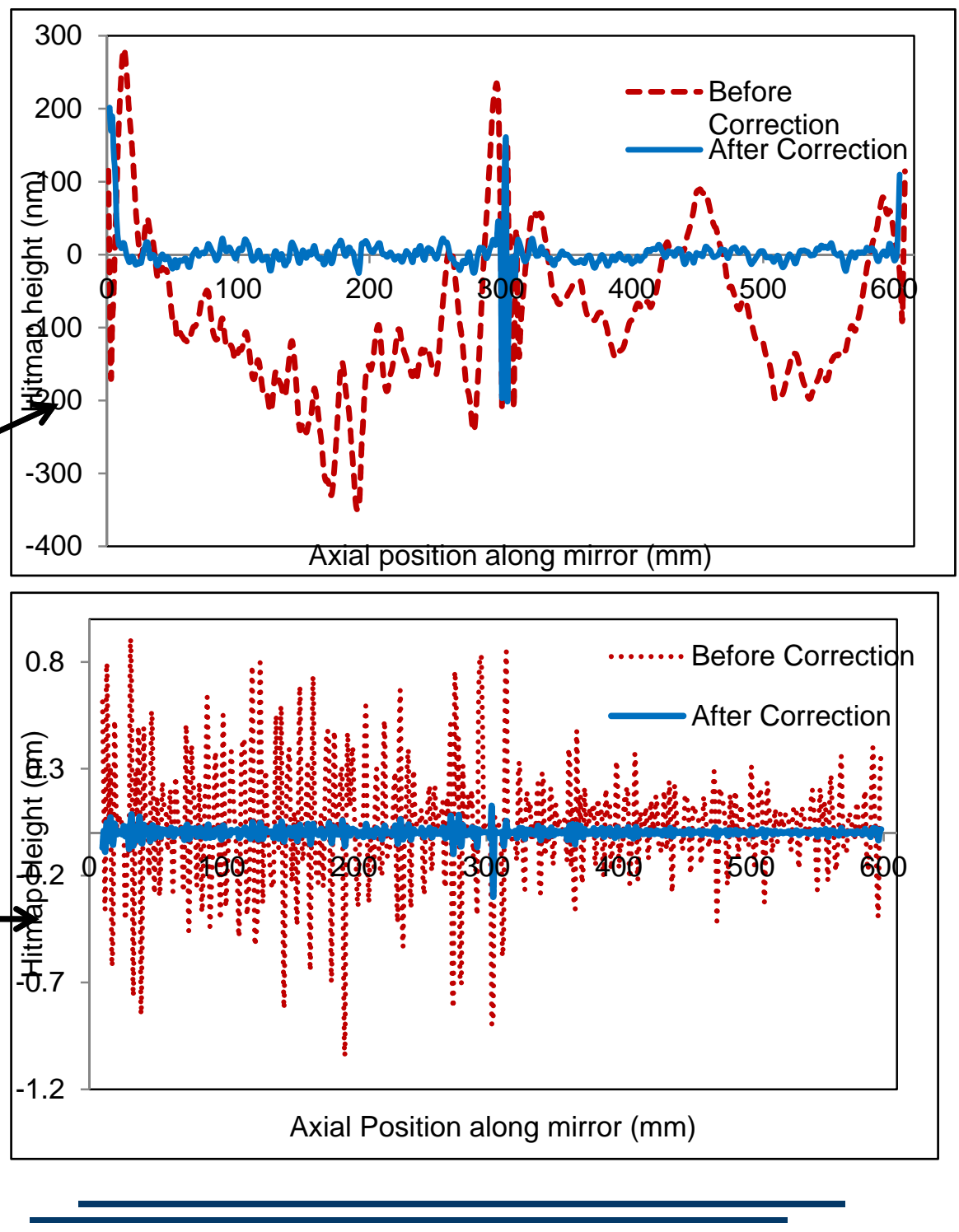


\section{Possible practical limitations}

- Variation of sputtered beam profile along the length of mirror particularly for short focal length mirrors

- Deviation in the simulated sputtered beam profile from actual profile, beam non-uniformities, etc

- Positional inaccuracy of the slit with respect to mirror

- Stress effects

- Metrology uncertainty 


\section{Metrology limitation}

Simulations performed on X-ray shell of 8 arc sec

simulated HPD

\begin{tabular}{|c|c|c|c|c|}
\hline $\begin{array}{l}\text { Correction } \\
\text { stage }\end{array}$ & $\begin{array}{c}\text { Average } \\
\text { deposition } \\
\text { amplitude } \\
(\mathrm{nm})\end{array}$ & $\begin{array}{c}\text { Slit-size } \\
(\mathrm{mm})\end{array}$ & $\begin{array}{l}\text { Metrology } \\
\text { uncertainty } \\
(\mathrm{nm})\end{array}$ & $\begin{array}{l}\text { Angular } \\
\text { resolution } \\
\text { (arc secs) }\end{array}$ \\
\hline \multirow{3}{*}{1} & \multirow{3}{*}{300} & \multirow{3}{*}{5} & \pm 0 & 3.6 \\
\hline & & & \pm 10 & 3.6 \\
\hline & & & \pm 50 & 7.3 \\
\hline \multirow{4}{*}{2} & \multirow{4}{*}{40} & \multirow{4}{*}{2} & \pm 0 & 0.6 \\
\hline & & & \pm 1 & 1 \\
\hline & & & \pm 5 & 2 \\
\hline & & & \pm 10 & 3.5 \\
\hline \multirow{4}{*}{3} & \multirow{4}{*}{4} & \multirow{4}{*}{1} & \pm 0 & 0.2 \\
\hline & & & \pm 0.5 & 0.2 \\
\hline & & & \pm 1 & 0.5 \\
\hline & & & \pm 2 & 0.8 \\
\hline
\end{tabular}

-Potential for uarc-second-level resolution - with MSFC's metrology equipment

- Sub-arc sec resolution could be possible with the state-of-art metrology equipment 


\section{Mirrors for Future Missions - Differential Deposition}

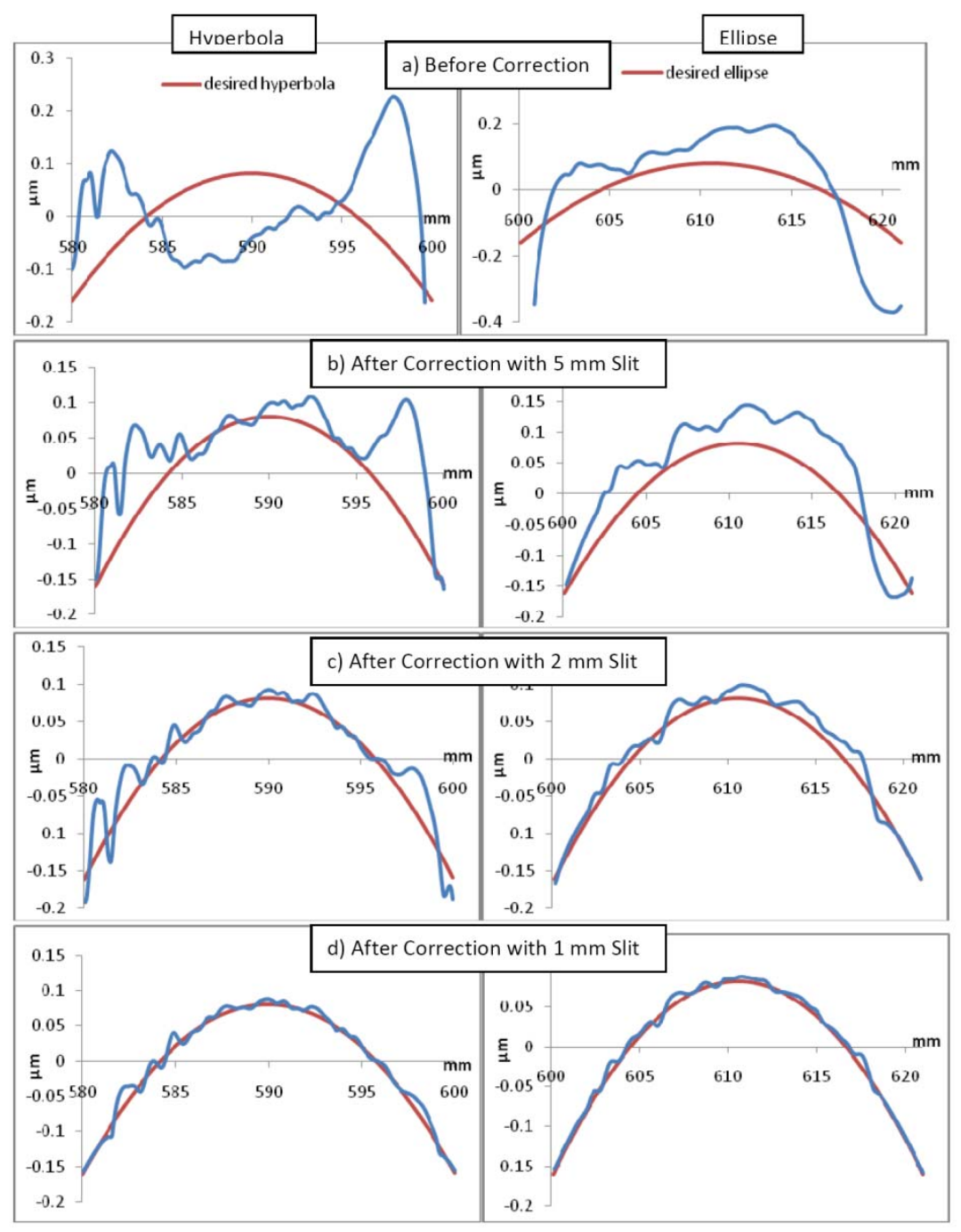

\begin{tabular}{|c|c|c|c|c|}
\hline $\begin{array}{l}\text { Correction } \\
\text { stage }\end{array}$ & $\begin{array}{c}\text { Average } \\
\text { deposition } \\
\text { amplitude } \\
\text { (nm) }\end{array}$ & $\begin{array}{l}\text { Slit- } \\
\text { size } \\
(\mathrm{mm})\end{array}$ & $\begin{array}{c}\text { Amplitude } \\
\text { uncertainty } \\
\text { (nm) }\end{array}$ & $\begin{array}{c}\text { Angular } \\
\text { resolution } \\
\text { (arcsec) }\end{array}$ \\
\hline \multirow[t]{3}{*}{1} & \multirow[t]{3}{*}{300} & \multirow[t]{3}{*}{5} & \pm 0 & 3.6 \\
\hline & & & \pm 10 & 3.6 \\
\hline & & & \pm 50 & 7.3 \\
\hline \multirow[t]{4}{*}{2} & \multirow[t]{4}{*}{40} & \multirow[t]{4}{*}{2} & \pm 0 & 0.6 \\
\hline & & & \pm 1 & 1.0 \\
\hline & & & \pm 5 & 2.0 \\
\hline & & & \pm 10 & 3.5 \\
\hline \multirow[t]{4}{*}{3} & \multirow[t]{4}{*}{4} & \multirow[t]{4}{*}{1} & \pm 0 & 0.2 \\
\hline & & & \pm 0.5 & 0.2 \\
\hline & & & \pm 1 & 0.5 \\
\hline & & & \pm 2 & 0.8 \\
\hline
\end{tabular}

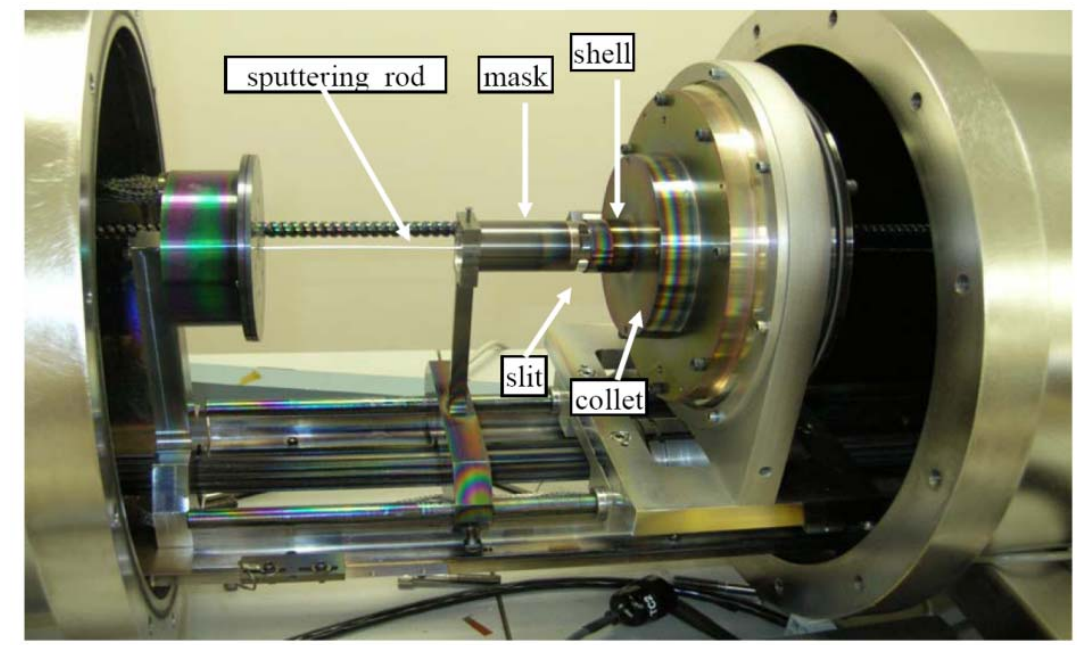

X-Ray Astronomy Group 


\section{Material and process selection}

\begin{tabular}{|c|c|c|c|c|c|c|c|}
\hline \multicolumn{4}{|c|}{ Platinum-Xenon } & \multicolumn{4}{|c|}{ Platinum-Argon } \\
\hline power & pressure & roughness & deposition rate & power & pressure & roughness & deposition rate \\
\hline 75 & 15 & 1.950 & 0.130 & 75 & 15 & 2.060 & 0.140 \\
\hline 90 & 15 & 2.043 & 0.230 & 90 & 15 & 1.933 & 0.190 \\
\hline 75 & 30 & 1.895 & 0.170 & 75 & 30 & 1.868 & 0.160 \\
\hline 90 & 30 & 1.810 & 0.250 & 90 & 30 & 2.083 & 0.220 \\
\hline \multicolumn{4}{|c|}{ Nickel-Xenon } & \multicolumn{4}{|c|}{ Nickel-Argon } \\
\hline power & pressure & roughness & deposition rate & power & pressure & roughness & deposition rate \\
\hline 75 & 15 & 1.915 & 0.290 & 75 & 15 & 1.995 & 0.180 \\
\hline 90 & 15 & 2.070 & 0.360 & 90 & 15 & 1.778 & 0.240 \\
\hline 75 & 30 & 3.093 & 0.240 & 75 & 30 & 2.260 & 0.220 \\
\hline 90 & 30 & 3.630 & 0.310 & 90 & 30 & 2.210 & 0.290 \\
\hline \multicolumn{4}{|c|}{ Tungsten-Xenon } & \multicolumn{4}{|c|}{ Tungsten-Argon } \\
\hline power & pressure & roughness & deposition rate & power & pressure & roughness & deposition rate \\
\hline 75 & 15 & 1.965 & 0.300 & 75 & 15 & 1.900 & 0.120 \\
\hline 75 & 30 & 1.805 & 0.290 & 75 & 30 & 2.125 & 0.290 \\
\hline 90 & 30 & 1.993 & 0.370 & 90 & 30 & - & - \\
\hline 75 & 50 & 2.075 & 0.290 & 75 & 50 & 1.998 & 0.310 \\
\hline 90 & 50 & 2.423 & 0.370 & 90 & 50 & 1.868 & 0.370 \\
\hline
\end{tabular}




\section{Proof of concept on few-cm-scale medical imaging optics}

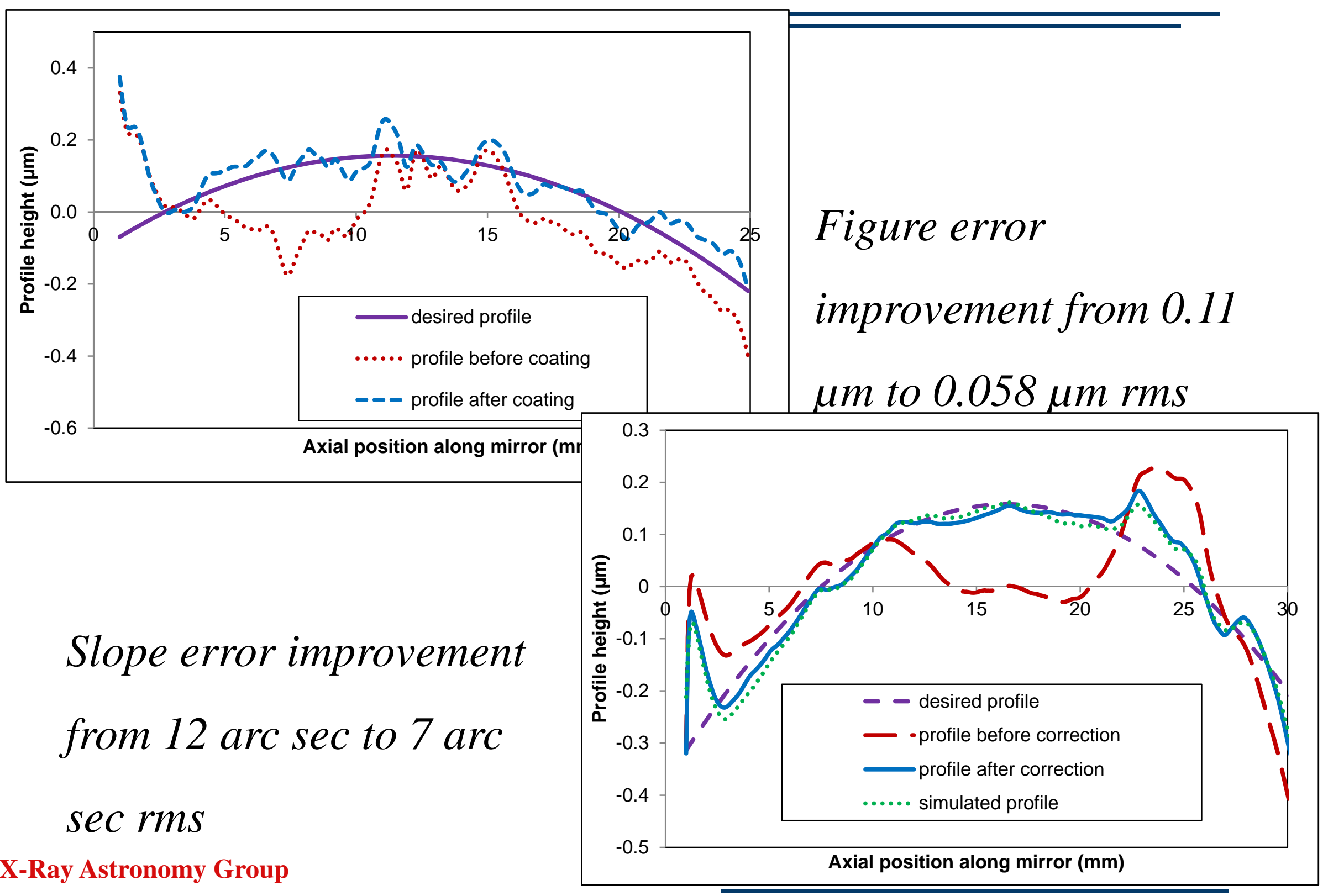




\section{Current Status}

- Since submitting this RFI response we have been notified of APRA / ARA funding

- This will allow us to build a custom system and demonstrate the technique on larger full shell (MSFC) and segmented (GSFC) optics

- We hope to be able to demonstrate 5 arcsec performance in 3 years

- To go beyond this, (arcsecond level) is very difficult to judge as we have not yet discovered the problems.

- May necessitate in-situ metrology, stress reduction investigations, correcting for gravity effects, correcting for temperature effects

- Some of this will become obvious in early parts of the investigation

- Top-of-head estimate - 5 years total and additional \$2-3M 


\section{Long Trace Profiler}

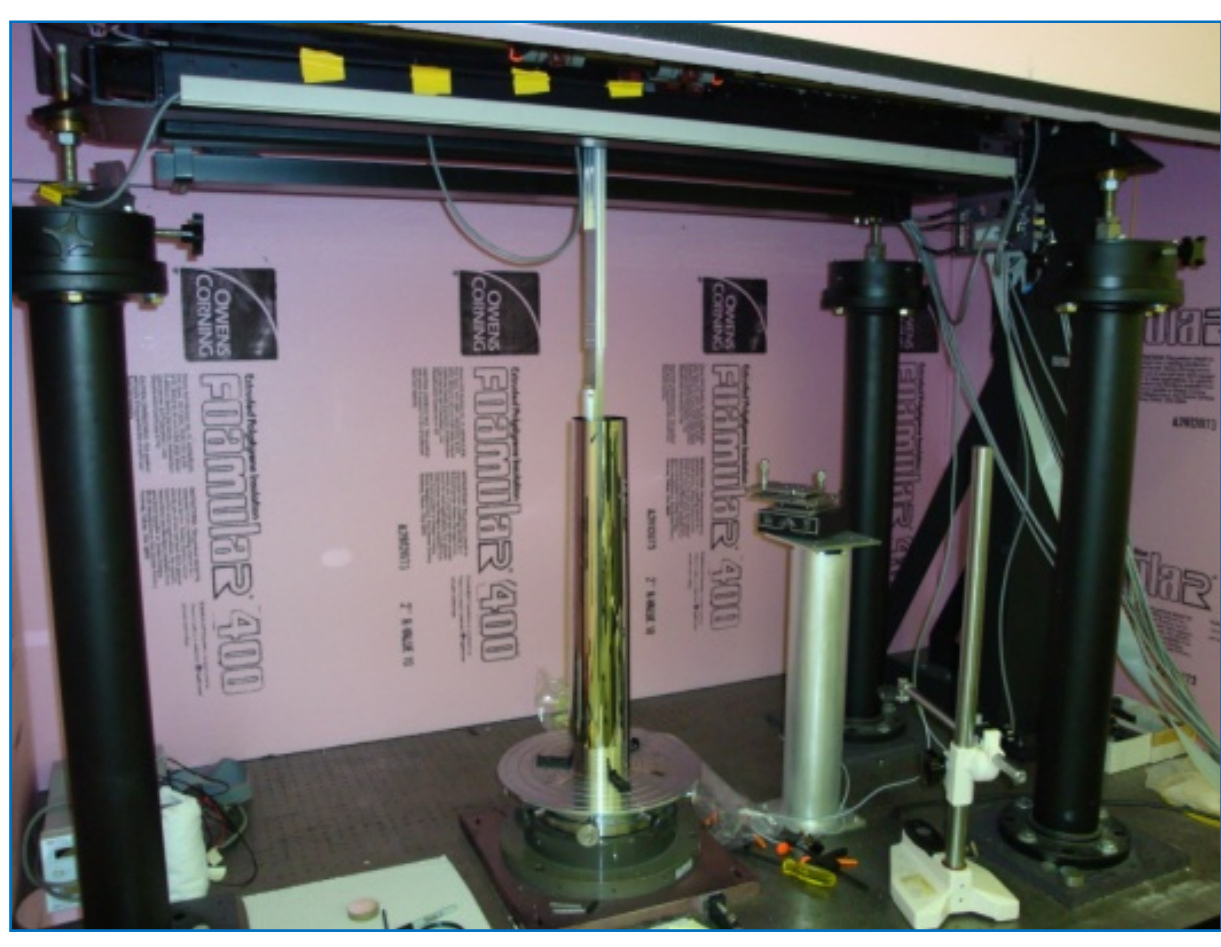

- Time taken to measure is about 5 mins for $300 \mathrm{~mm}$ sample length

X-Ray Astronomy Group
-Pencil beam interferometry

- Measure spatial wavelengths starting from $1 \mathrm{~mm}$ upto several 100's of $\mathrm{mm}$

- Laser beam scans point-by-point - slope data

- Position of the beam at the detectordirect measure of the slope

- Accuracies possible <1 urad

-Multiple measurements - 2D topography 


\section{Increase the speed?}

- Make use of advanced technology

- Higher resolution 2D detectors

- Stable optical sources

- Increase the speed \& accuracies of measurements

- Higher density data - complete information of mandrel or shell

- Multiple beams - simultaneous measurements? 


\section{Multi-beam LTP}

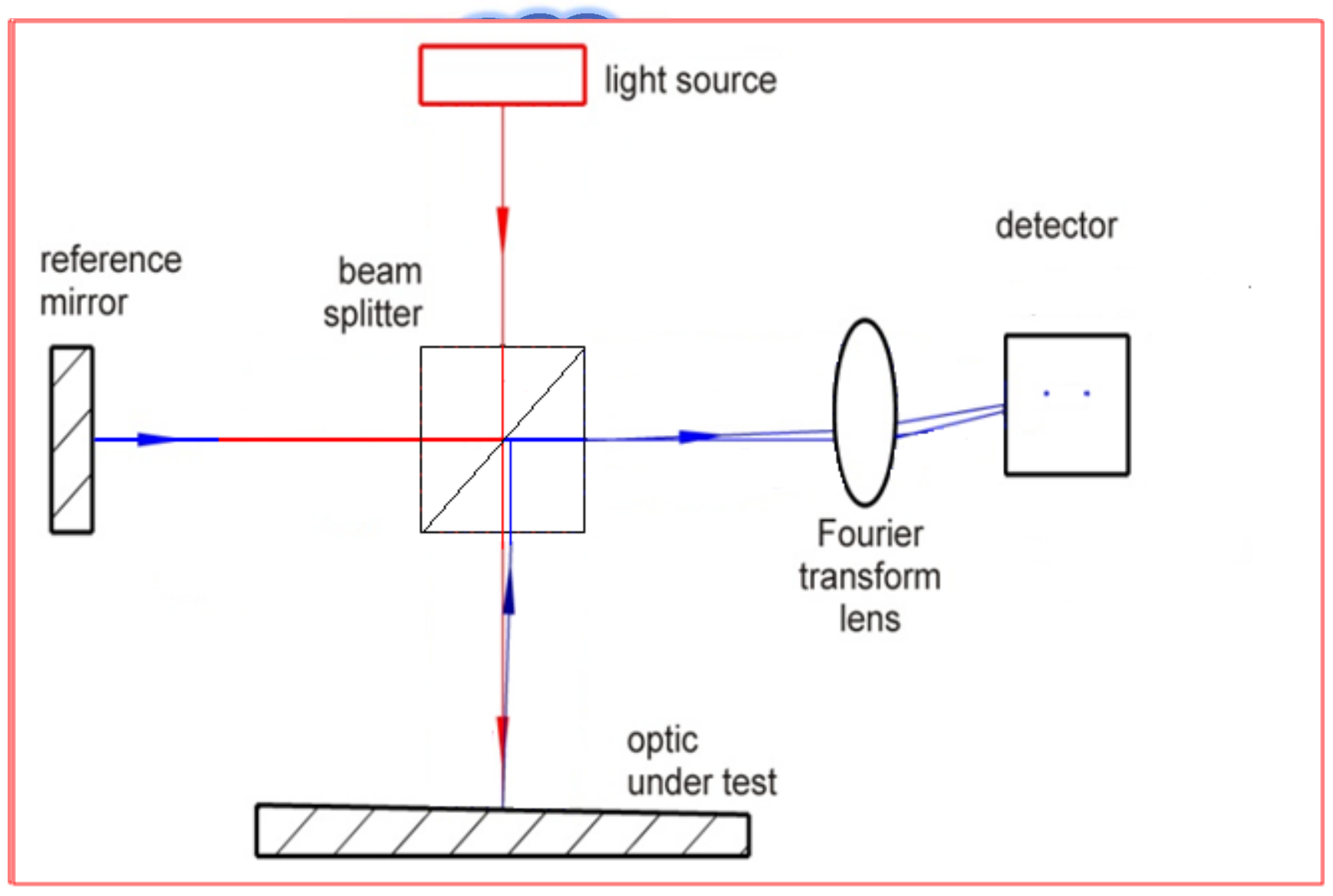

-Proof-of-concept

- To study the limitations of the approach X-Ray Astronomy Group
- Number of beams - 5 to 10

- Spatial separation of beams - 1 to $2 \mathrm{~mm}$ 


\section{Multi-beam LTP Requirements}

- Target - decrease the time of measurement - reasonable accuracy

- Existing systems

- linear array detector - $25 \mu \mathrm{m} \times 2.5 \mathrm{~mm}$ pixel size

- $1 \mathrm{~m}$ focal length FT lens

- Lens and detector $\rightarrow 0.25 \mu \mathrm{rad}$

- 2D detector requirements

- multiple beams in one plane and beam translation on other plane

- angular range +/- $15 \mathrm{mrad}$

\begin{tabular}{|r|c|c|c|c|c|}
\hline fl $(\mathrm{mm})$ & 500 & 550 & $\mathbf{6 0 0}$ & $\mathbf{7 0 0}$ & $\mathbf{8 0 0}$ \\
\hline pixel $(\mu \mathrm{m})$ & & & & & \\
\hline $\mathbf{4}$ & 0.12 & 0.11 & 0.10 & 0.09 & 0.08 \\
\hline $\mathbf{8}$ & 0.24 & 0.22 & 0.20 & 0.17 & 0.15 \\
\hline 10 & 0.30 & 0.27 & 0.25 & 0.21 & 0.19 \\
\hline 14 & 0.42 & 0.38 & 0.35 & 0.30 & 0.26 \\
\hline & & & & & \\
\hline 18 & 0.54 & 0.49 & 0.45 & 0.39 & 0.34 \\
\hline
\end{tabular}

- Detector atleast $20 \mathrm{~mm} \times 20 \mathrm{~mm}$ area

- $<8 \mu \mathrm{m}$ pixel size 


\section{CCD detector \& FT lens}

- Detector Procured (1 ${ }^{\text {st }}$ Vision's JAI AM-1600GE)

- $36 \mathrm{~mm} \times 24 \mathrm{~mm}$ area

- $7.4 \times 7.4 \mu m$ pixel size

- 3.04 fps

- Custom designed FT lens

- $500 \mathrm{~mm}$ focal length

- $50 \mathrm{~mm}$ diameter

- Low distortion - minimize the effects of lens on systematic errors 


\section{FT lens design}

- Less number of elements - two element system

- Air-spaced doublet lens

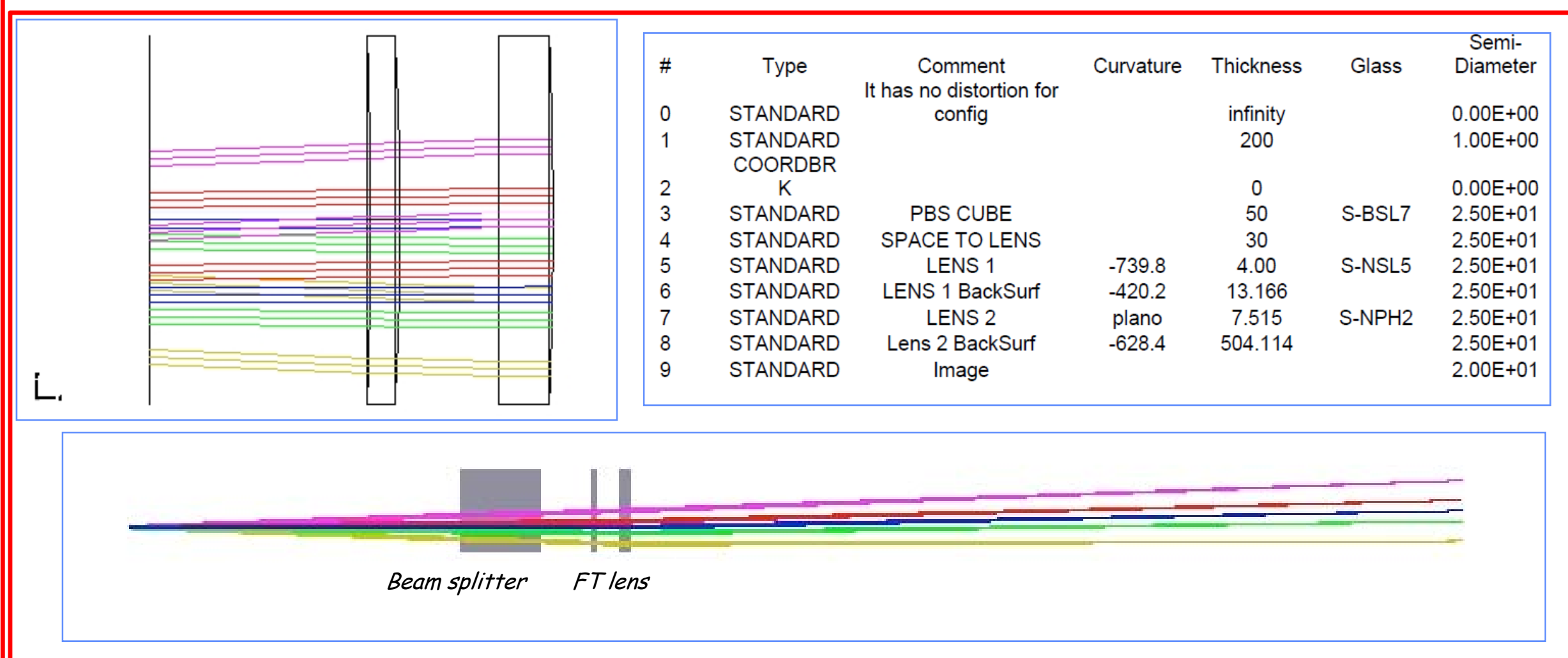

\section{- Anti-reflection coating}




\section{Multiple beam generation}

- Multiple beams of almost equal intensity

- Spatial separation $(2.4 \mathrm{~mm})$

- Angular separation (250 Arad)

- Wedged etalon approach

- Customized coating on one side

- $100 \%$ reflection coating on the other

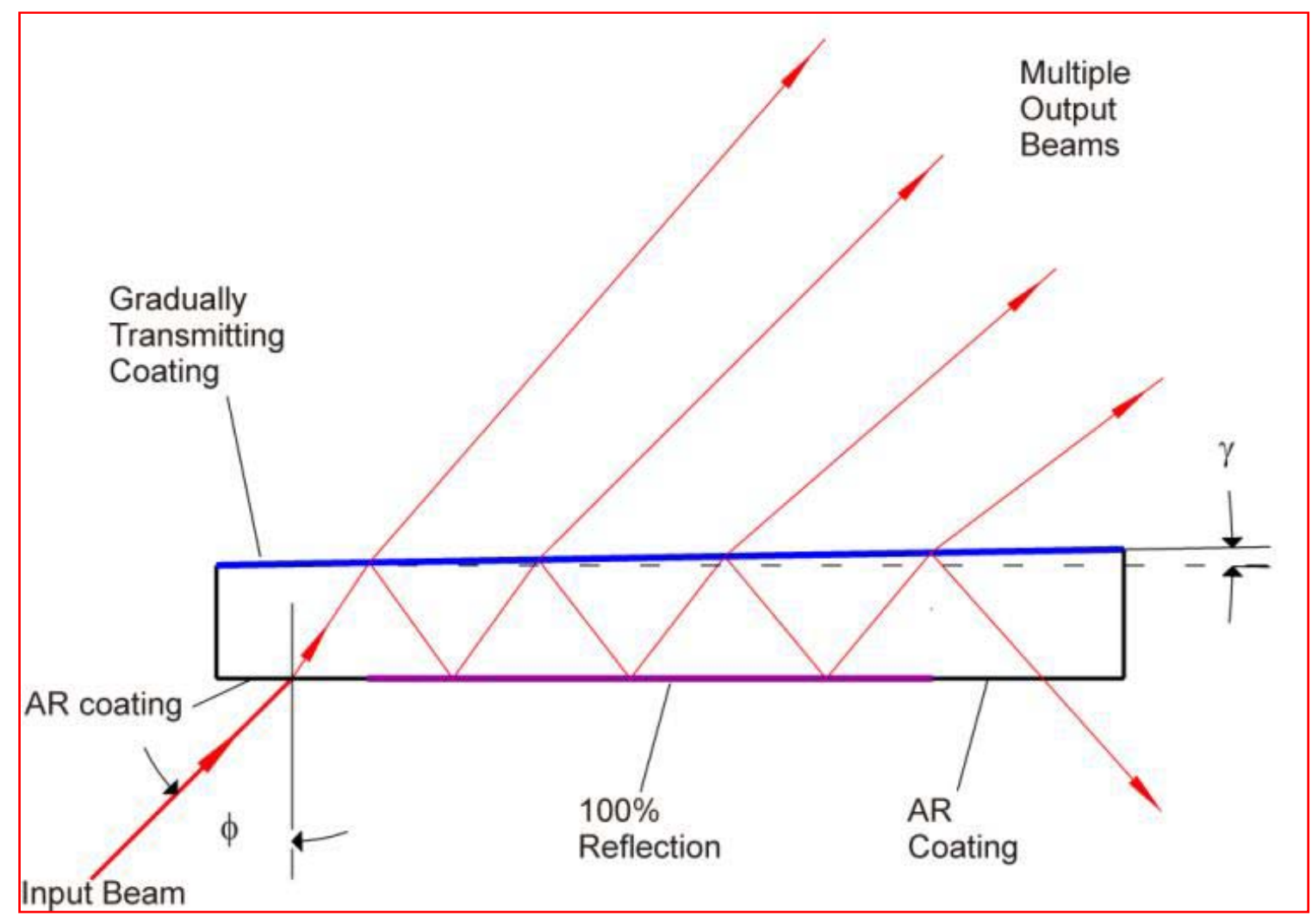

- Dimension-50 $550 \times 3 \mathrm{~mm}$

- Wedge - 60 urad 


\section{Coating - wedged etalon}

Possible approaches

- Continuous ideal gradient coating

- Linear approximation to ideal

- Multilayers

- Discrete coatings - each

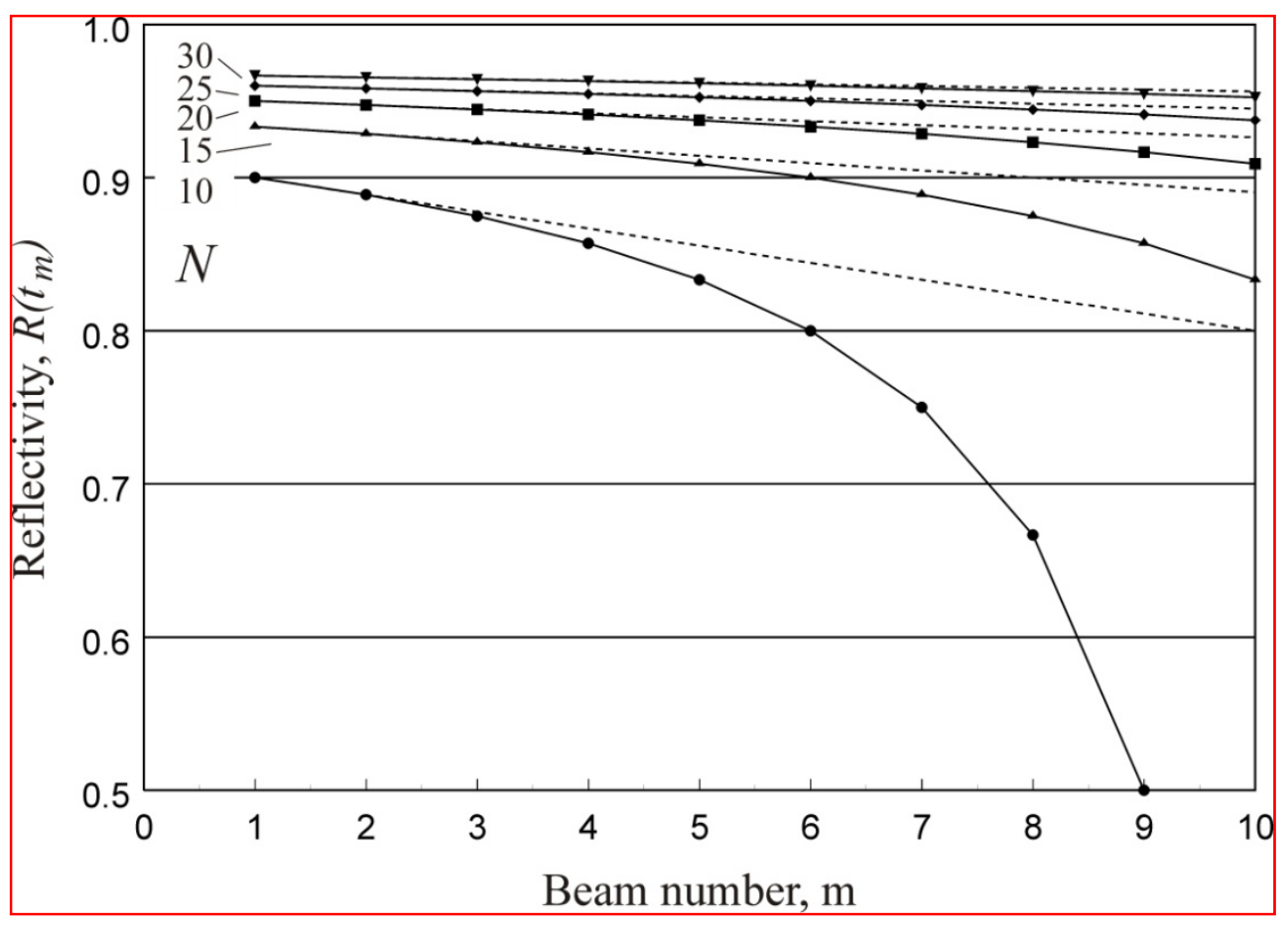
with constant reflectivity 


\section{Multiple beam generation - wedged etalon}

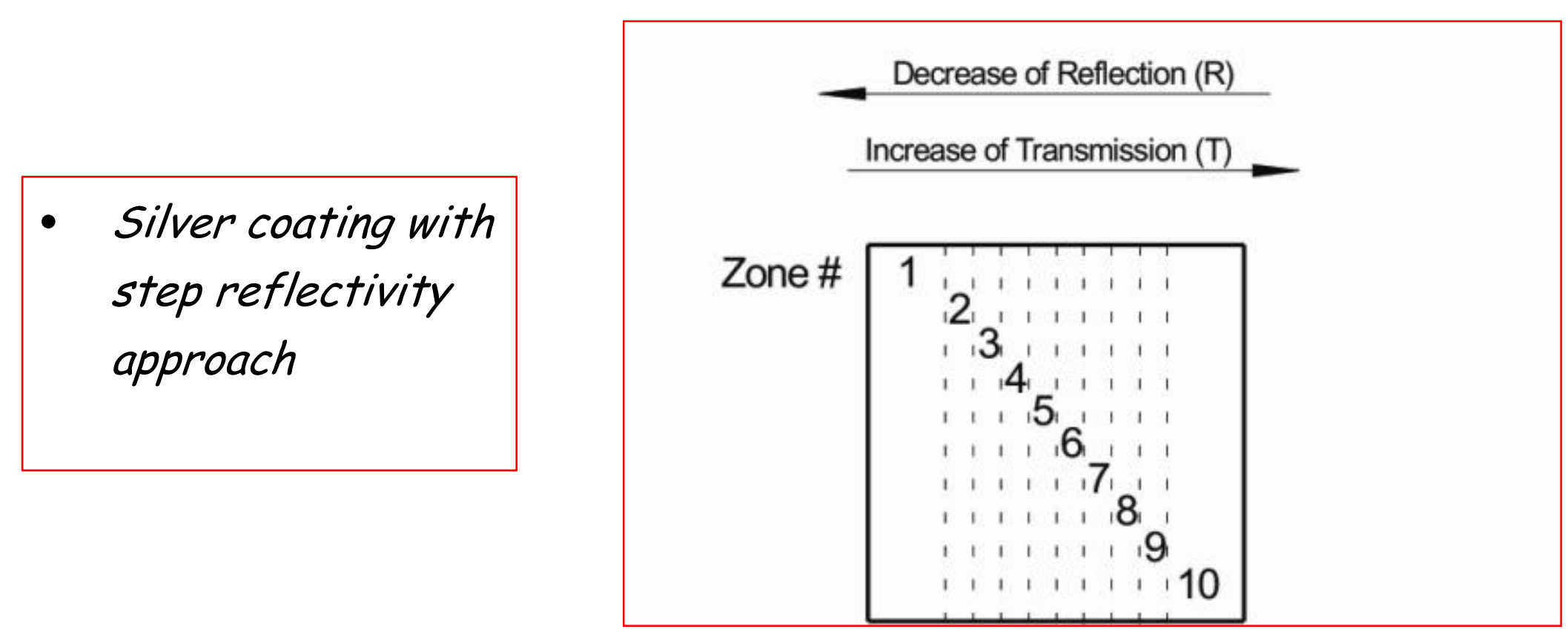

\begin{tabular}{|l|c|c|c|c|c|c|c|c|c|c|}
\hline Zone & 1 & 2 & 3 & 4 & 5 & 6 & 7 & 8 & 9 & 10 \\
\hline $\mathrm{R}_{\mathrm{Z}}, \%$ & 93.33 & 92.86 & 92.31 & 91.67 & 90.91 & 90.00 & 88.89 & 87.50 & 85.71 & 83.33 \\
\hline $\mathrm{T}_{\mathrm{Z}}, \%$ & 6.67 & 7.14 & 7.69 & 8.33 & 9.09 & 10.00 & 11.11 & 12.50 & 14.29 & 16.67 \\
\hline
\end{tabular}




\section{Cube beamsplitter}

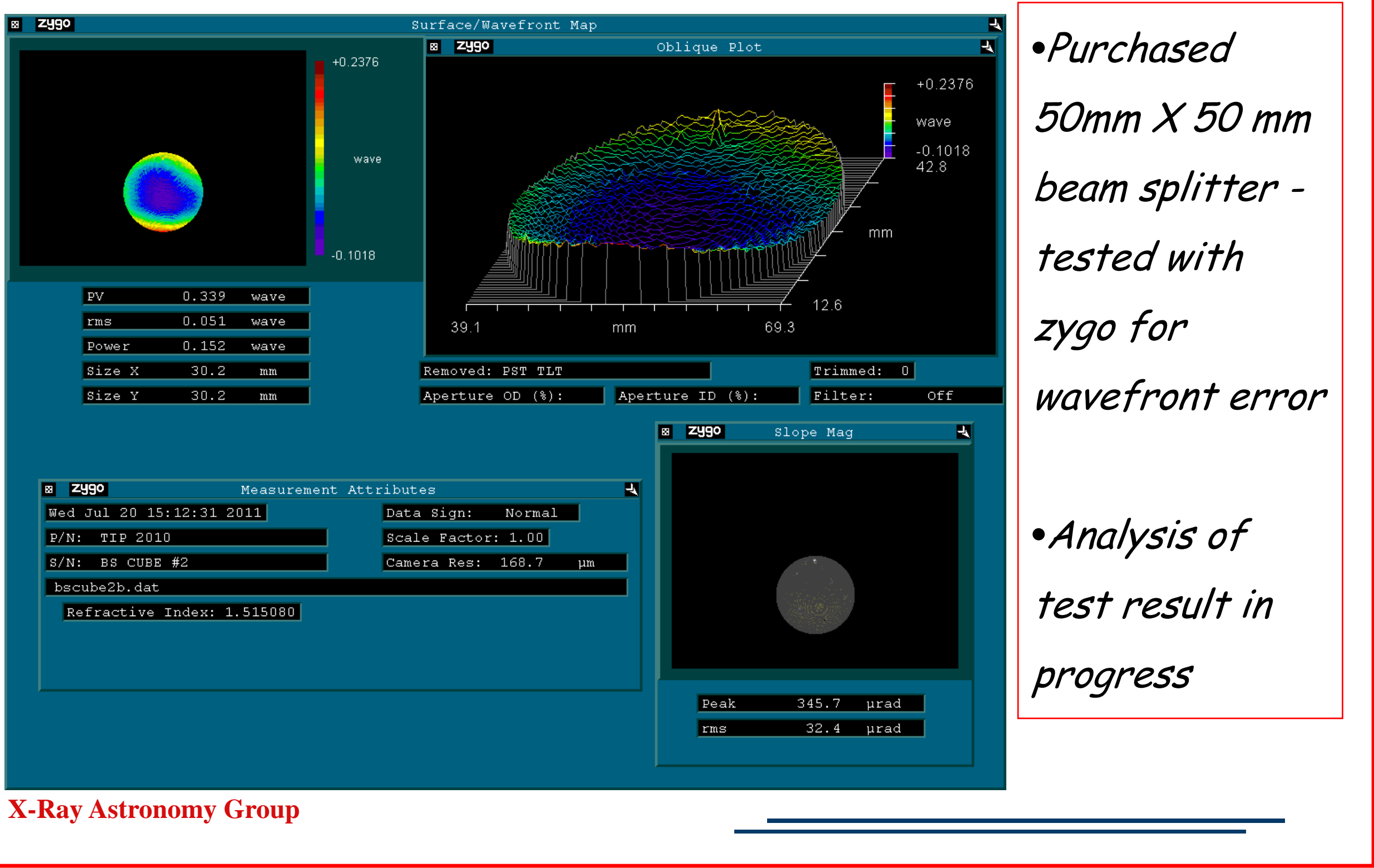




\section{Software}

- Berkeley National Labs - provided software code

- 3 beams - being adapted to new detector for multiple beams - Maxima of single peak

- Tests are underway to check the speed of readout \& processing - 0.5 fps for full frame of $4872 \times 3248-1.3$ fps for partial frame of $4872 \times 800$
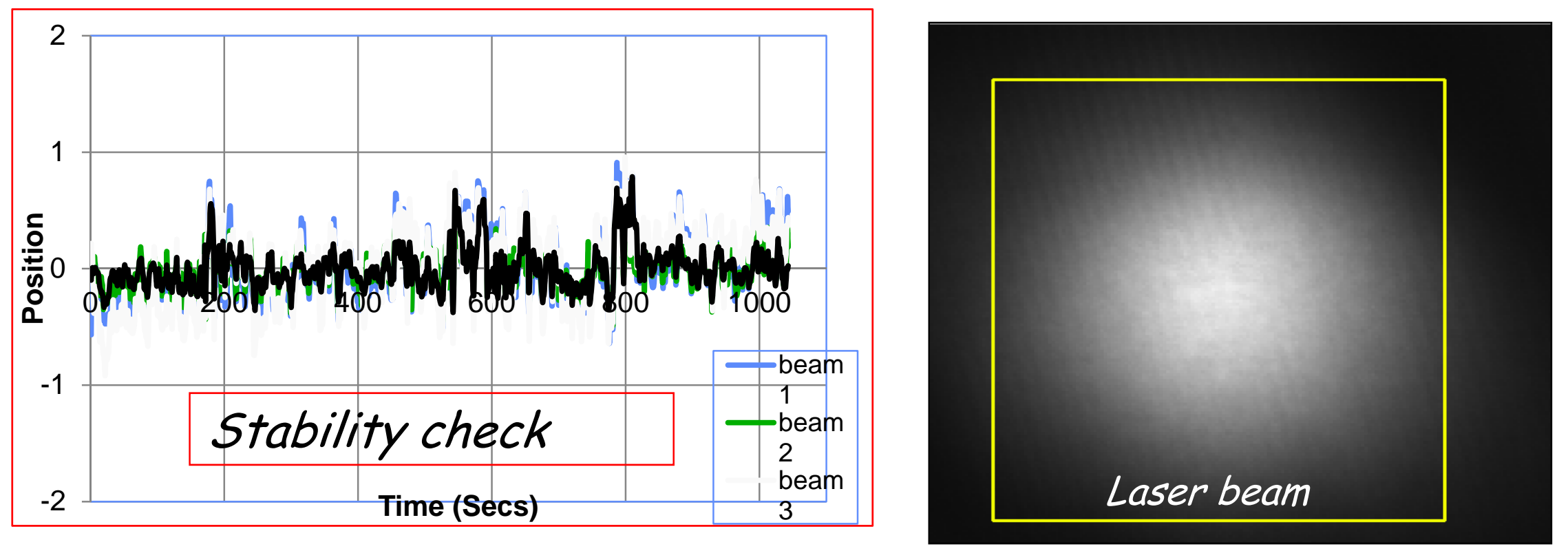

X-Ray Astronomy Group 


\section{Future work}

- Immediate work

$\checkmark$ Replace detector

$\checkmark$ Etalon test \& analysis

$\checkmark$ Detector software

- Assemble components

- Test measurements

- Modular approach 